Article

\title{
Impact of Soil Moisture Initialization in the Simulation of Indian Summer Monsoon Using RegCM4
}

\author{
Suman Maity ${ }^{1}\left(\mathbb{D}\right.$, Sridhara Nayak $^{2, *} \mathbb{( D},{\text { Kuvar Satya } \operatorname{Singh}^{3}, \text { Hara Prasad Nayak }^{4}(\mathbb{D} \text { and Soma Dutta }}^{5}$ \\ 1 Research Institute for Global Change, Japan Agency for Marine-Earth Science and Technology, \\ Yokohama 236-0001, Japan; suman.buie@gmail.com \\ 2 Disaster Prevention Research Institute, Kyoto University, Gokasho, Uji, Kyoto 6110011, Japan \\ 3 Center for Disaster Mitigation and Management (CDMM), Vellore Institute of Technology, \\ Vellore 632014, India; kuvarsatya.singh@vit.ac.in \\ 4 School of Earth Ocean and Climate Sciences, Indian Institute of Technology Bhubaneswar, \\ Bhubaneswar 752050, India; hpn10@iitbbs.ac.in \\ 5 Farmneed AgriBusiness Private Limited, Salt Lake 700091, India; soma.d@farmneed.com \\ * Correspondence: nayak.sridhara.2n@kyoto-u.ac.jp
}

Citation: Maity, S.; Nayak, S.; Singh, K.S.; Nayak, H.P.; Dutta, S. Impact of Soil Moisture Initialization in the Simulation of Indian Summer Monsoon Using RegCM4. Atmosphere 2021, 12, 1148. https://doi.org/ 10.3390/atmos 12091148

Academic Editor: Anita Drumond

Received: 2 August 2021

Accepted: 31 August 2021

Published: 5 September 2021

Publisher's Note: MDPI stays neutral with regard to jurisdictional claims in published maps and institutional affiliations.

Copyright: (c) 2021 by the authors. Licensee MDPI, Basel, Switzerland. This article is an open access article distributed under the terms and conditions of the Creative Commons Attribution (CC BY) license (https:/ / creativecommons.org/licenses/by/ $4.0 /)$.

\begin{abstract}
Soil moisture is one of the key components of land surface processes and a potential source of atmospheric predictability that has received little attention in regional scale studies. In this study, an attempt was made to investigate the impact of soil moisture on Indian summer monsoon simulation using a regional model. We conducted seasonal simulations using a regional climate model (RegCM4) for two different years, viz., 2002 (deficit) and 2011 (normal). The model was forced to initialize with the high-resolution satellite-derived soil moisture data obtained from the Climate Change Initiative (CCI) of the European Space Agency (ESA) by replacing the default static soil moisture. Simulated results were validated against high-resolution surface temperature and rainfall analysis datasets from the India Meteorology Department (IMD). Careful examination revealed significant advancement in the RegCM4 simulation when initialized with soil moisture data from ESA-CCI despite having regional biases. In general, the model exhibited slightly higher soil moisture than observation, RegCM4 with ESA setup showed lower soil moisture than the default one. Model ability was relatively better in capturing surface temperature distribution when initialized with high-resolution soil moisture data. Rainfall biases over India and homogeneous regions were significantly improved with the use of ESA-CCI soil moisture data. Several statistical measures such as temporal correlation, standard deviation, equitable threat score (ETS), etc. were also employed for the assessment. ETS values were found to be better in 2011 and higher in the simulation with the ESA setup. However, RegCM4 was still unable to enhance its ability in simulating temporal variation of rainfall adequately. Although initializing with the soil moisture data from the satellite performed relatively better in a normal monsoon year (2011) but had limitations in simulating different epochs of monsoon in an extreme year (2002). Thus, the study concluded that the simulation of the Indian summer monsoon was improved by using RegCM4 initialized with high-resolution satellite soil moisture data although having limitations in predicting temporal variability. The study suggests that soil moisture initialization has a critical impact on the accurate prediction of atmospheric circulation processes and convective rainfall activity.
\end{abstract}

Keywords: convective rainfall; land surface model; mixed convection scheme; regional climate model; satellite-derived soil moisture

\section{Introduction}

The strong impact of land surface processes is well recognized in modulating the weather and climate system in subseasonal to seasonal and even longer time scale. Land surface acts as an interface between the biosphere and the overlying atmosphere. It interacts with the atmosphere through the exchange of mass, momentum and energy and hence is 
considered as the lower boundary of the atmosphere at approximately 30\% of the Earth's surface [1]. It is also well understood that the Earth's surface is the reservoir of our main energy resources from solar radiation. Both short and long wave forms of solar radiation are absorbed by the land surface and reemitted. When releasing the energy through the planetary boundary layer, the Earth's surface works like a separator. It redistributes the net incoming radiative energy into various fluxes such as sensible, latent and other ground fluxes. Hence, the energy required to develop and sustain any weather system over landmass, is supplied from the underlying land surface [2-5]. Therefore, the landatmosphere interaction plays a vital role in modulating the weather and climate systems on a regional and global scale [6-10]. Due to its immense impact, the functions of the land surface have been explored extensively in observation as well as modeling studies across the globe [9-14].

Land surface-atmosphere interaction may be either a positive, negative or both feedback mechanism between the atmosphere and different land surface characteristics such as soil moisture, soil temperature, soil types, vegetation cover, snow cover, etc. Each of them is not of similar importance for a weather system over a region. In particular, soil moisture is an important component of the global water budget and hydrology cycle $[1,8,15]$. The function of soil moisture may be described in two ways. Primarily, rate of evaporation from the land surface is determined by the soil moisture quantity which controls the moisture supply to the atmosphere. Secondly, as mentioned earlier, it mainly partitions the net absorbed solar radiation into fluxes. It is mentioned by Dutta et al. [16] that soil moisture and snow cover are the two leading land surface variables that have a potential impact on the variation of weather systems if the effect of sea surface temperature is excluded.

Climate downscaling using a regional climate model (RCM) is well accepted and widely used for the simulation of various weather and climate systems for the past several decades. It is demonstrated in numerous earlier works of literature [17-22] that the RCMs show better competence in simulating climatic features due to better representation of the subgrid scale physical process and topography than the global circulation model. Land surface processes mostly occur at a subgrid-scale but play an important role in controlling weather systems $[6,7,23]$. Through evaporation, the exchange of heat and moisture fluxes from the land surface to the atmosphere helps form convection and precipitation. Proper representation of soil moisture is therefore extremely crucial for the numerical weather forecasting as well as climate simulations on seasonal, annual and decadal scale using fully coupled RCMs. In each state-of-the-art RCM, physical parameterization of the land surface is taken care of through different land surface models (LSM henceforth). The soil moisture initialization technique is different in different LSMs. However, providing an accurate state of the soil parameters has a serious impact on evaluating the weather and climate modes which are associated with the retrospective research based on the terrestrial hydrology cycle. Therefore, better simulation of atmospheric processes can be achieved through initializing climate models with realistic observational/reanalysis soil moisture datasets.

Several kinds of research have already been carried out to emphasize the impact of land surface model initialization with realistic soil moisture datasets $[6,7,24-33]$. Fennessy and Shukla [24] studied the importance of initial soil wetness in seasonal prediction with dynamical models. They concluded that the effect of initial soil wetness is local and greatest in the near-surface fields, viz. evaporation, surface temperature and precipitation. Douville and Chauvin [25] used a land surface scheme that was forced with meteorological observation and analysis using a relaxation technique and inferred that the relaxation positively impacts both model climatology and variability at an interannual scale. Kanamitsu et al. [27] showed that the predictive ability of the initial soil moisture is higher in arid/semi-arid regions and has a sound impact on surface temperature simulation. Douville [28] investigated the effect of soil moisture on climate variability and potential predictability and highlighted its strong contribution to climate variability.

Moufouma-Okia and Rowell [2] investigated the sensitivity of soil moisture initialization on the West African monsoon by using an RCM and revealed that specification of 
initial soil moisture is slightly sensitive to the West African monsoon rainfall. Douville [3] highlighted the significant impact of soil moisture on regional climate and suggested further comprehensive and systematic investigation. Bisselink et al. [4] performed a similar study by initializing an RCM with satellite derived soil moisture data and showed greater impact during dry years. Suarez et al. [7] performed a numerical experiment for three synoptic events using two different mesoscale models with varying soil moisture. They illustrated that the rainfall increases (decreases) with enhanced (reduced) soil moisture, respectively. These studies indicate that the soil moisture significantly affects the weather and climate simulation, but varies from region to region. However, no studies have yet been discussed in this context over the Indian region.

Among the various RCMs available, the regional climate modeling system which is commonly abbreviated as RegCM of the International Center for Theoretical Physics (ICTP, Italy) has become remarkably popular due to its successful application towards numerous scientific studies [15,17-22,30,34-37] and many studies have tested its performance over Indian regions [17-22,37]. In the context of soil moisture, RegCM is also used over various regions [30,31,38]. Hu et al. [38] argued that the treatment of soil moisture should be paid more attention while performing an experiment on soil moisture data assimilation using RegCM over China. Patarcic and Brankovic [30] investigated the ability of surface temperature seasonal forecasting over Europe using RegCM by initializing it with three different types of soil moisture conditions during summer and winter times. Their study showed that the systematic error was reduced and deterministic ability was improved during summer using realistic soil moisture data. Liu et al. [31] evaluated the impact of soil moisture using RegCM simulation. They showed that initialization with wet (dry) soil moisture anomalies increased (reduced) the subsequent precipitation amount and reduced (increased) surface temperature. Due to sparse observation networks, the availability of accurate soil moisture data (either observation, reanalysis or both) in the past was very rare. Nowadays, different organizations offer accessibility to satellite-derived as well as reanalysis soil moisture datasets. The Climate Change Initiative (CCI) of the European Space Agency (ESA) is one such piece of data publicly released in 2015. This dataset has been successfully applied in some observational [39] and modeling studies [40] over other regions across the globe. However, it is not extensively explored over Indian regions. Although few observational studies over India are available in the literature $[8,10,11]$, it is not comprehensively used in modeling studies. This study mainly deals with the soil moisture initialization over India to understand its role on the seasonal simulation (May-September) of the Indian summer monsoon (ISM) using RegCM. To our knowledge, our attempt to investigate the impact of soil moisture on ISM using a regional model is the first over India. The rest of the paper is structured as follows: brief model information, experimental design, descriptions of the various datasets and validation strategy are discussed in Section 2. Results are described in Section 3 followed by discussion, conclusion, limitation and future scope in Sections 4-6, respectively.

\section{Materials and Methods}

\subsection{Model Description}

In the present study, RegCM v.4.4.5 (RegCM4 henceforth) is employed. It is a compressible, hydrostatic, terrain-following, finite difference, limited area model with a similar dynamical core to that of its previous version (RegCM3 [41]). The model offers a variety of parameterization schemes to represent different physical processes. Cumulus convection is represented using five major schemes such as Kuo [42], Grell [43], MIT [44], Tiedke [45] and Kain-Fritsch [46]. Due to variation in performance, RegCM4 shows flexibility of using different schemes separately over land and ocean, referred to as "mixed" schemes. Land surface processes are represented using two LSMs, namely, the BATS scheme [47] as well as CLM (v.3.5 [48]; v.4.5 [49]). Radiative transfer package from the global model CCM3 [50], planetary boundary layer from Holtslag [51] as well as University of Washington [52] are also available in RegCM4. A detailed description of other available physics schemes, viz., 
ocean fluxes parameterization schemes, interactive aerosol schemes and interactive lake models are described in Giorgi et al. [15].

In this study, we focused on the soil moisture initialization in the seasonal simulation of ISM using RegCM4. Two LSMs differ with their formulation in various aspects. One of the major disparities is in the description of the soil moisture column. BATS is composed of three soil moisture layers with varying depth from $10 \mathrm{~cm}$ to $3 \mathrm{~m}$ [35]. On the other hand, the CLM soil column consists of 10 unevenly distributed soil layers at $1.8 \mathrm{~cm}, 2.8 \mathrm{~cm}$, $4.6 \mathrm{~cm}, 7.5 \mathrm{~cm}, 12.4 \mathrm{~cm}, 20.4 \mathrm{~cm}, 33.6 \mathrm{~cm}, 55.4 \mathrm{~cm}, 91.3 \mathrm{~cm}$ and $113.7 \mathrm{~cm}$ depth, for a total depth of $3.4 \mathrm{~m}$ [53]. In the earlier version of RegCM, soil moisture was initialized using static soil water content relative to saturation as a function of land cover type [54]. Patarcic and Brankovic [30] suggested that this technique is a crude way of defining the initial soil moisture which includes neither seasonal nor interannual variation. Due to that, the model took a higher spin-up time to become stable, particularly for deeper soil layers. Considering this, RegCM4 offers the option to be initialized using climatological soil moisture data both in CLM and BATS $[29,55]$ along with the default static soil moisture. After being initialized from the soil moisture climatology, RegCM4 evolves independently with its own internal water balance equation [30], which would reduce sudden shock to the model at the initial time step and consequently decreases the spin-up time at the deeper soil layer of the model $[29,53]$.

\subsection{Experimental Design}

Seasonal simulation (1 May, 00UTC-30 September, 18UTC) of ISM is conducted using RegCM4 for two different years, viz., 2002 and 2011 encompassing the geographical area encompassing $30^{\circ} \mathrm{E}-120^{\circ} \mathrm{E}, 15^{\circ} \mathrm{S}-45^{\circ} \mathrm{N}$ (Figure 1) at $30 \mathrm{~km}$ horizontal resolution. According to the India Meteorological Department (IMD), India did not face any excess monsoon year during the last few decades subsequent to 1988 . However, the country witnessed a severe drought in 2002 with $81 \%$ ISM rainfall of its long period average [56]. On the other hand, 2011 was a normal year with $102 \%$ ISM rainfall of its long period average. Model configuration setup is provided in Table 1 [57]. Simulation during May is considered as spin-up and excluded from the subsequent analysis.

Table 1. Overview of the model considered for this study.

\begin{tabular}{cc}
\hline Contents & Description \\
\hline Model domain & South Asia $\left(30^{\circ} \mathrm{E}-120^{\circ} \mathrm{E} ; 5^{\circ} \mathrm{S}-45^{\circ} \mathrm{N}\right)$ \\
Resolution & Horizontal: $30 \mathrm{~km}$, vertical: 23 terrain \\
Land surface & following $\sigma$ levels \\
Cumulus convection & CLM4.5 [49] \\
Cumulus closure & Grell [43] over ocean and MIT [44] over land \\
Explicit moisture & Arakawa and Schubert [58] \\
Ocean flux & SUBEX [59] \\
& Zeng [60] \\
\hline
\end{tabular}

By default, RegCM4 is initialized with the static soil moisture data through the BATS lookup table. In this study, the model is forced to begin with high-resolution satellitederived soil moisture data $[61,62]$ from the Climate Change Initiative (CCI) of the European Space Agency (ESA) (referred as ESA-CCI; http:/ / www.esa-soilmoisture-cci.org; accessed on 15 July 2019). Detailed information of this dataset is given in the following subsection. 


\section{Topography}

\section{meter}

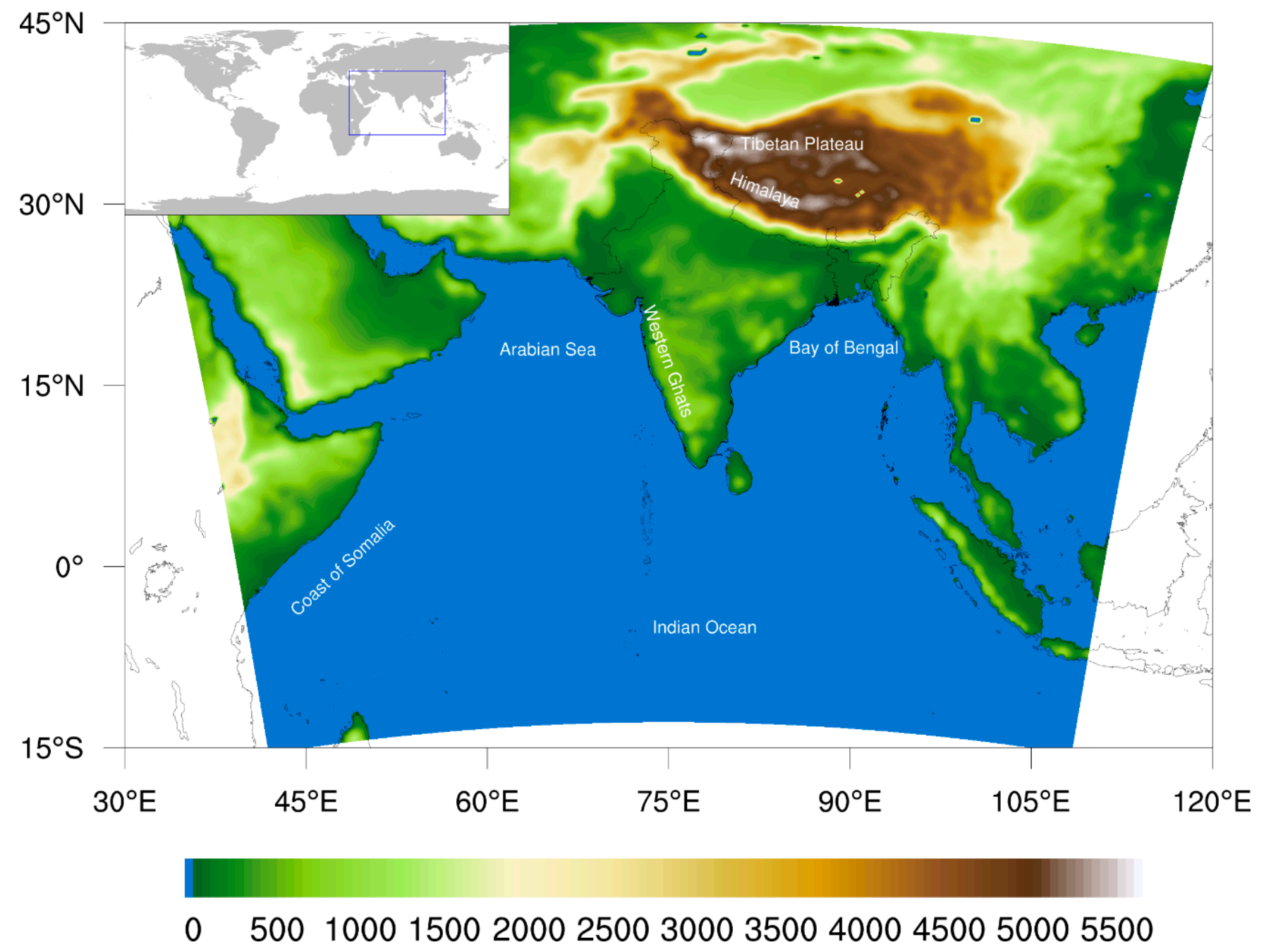

Figure 1. Map of the simulation domain used in the study. The domain encompasses $30^{\circ} \mathrm{E}-120^{\circ} \mathrm{E}, 15^{\circ} \mathrm{S}-45^{\circ} \mathrm{N}$ in Lambert Conformal map projection. Different color shades specify the topographical height above mean sea level (in meters).

\subsection{Data}

The model was forced with six-hourly ERA-Interim reanalysis (EIN75 [63] hereafter) data at $0.75^{\circ} \times 0.75^{\circ}$ resolution. Topography and land use were obtained from the United States Geological Survey and Global Land Cover Characterization [64] global data at 10 min resolution.

The sea surface temperature from optimum interpolation weekly mean sea surface temperature [65] was fed into the model at $1^{\circ} \times 1^{\circ}$ resolution from National Oceanic and Atmospheric Administration. Additional datasets including land cover, soil texture, soil color, leaf area index, plant functional type, emission factors, snow data, etc. required for CLM4.5 [49] were obtained from the RegCM data portal (http:/ / clima-dods.ictp.it/Data/ RegCM_Data/CLM45/; accessed on 2 June 2019). Simulated surface temperature and rainfall were validated against high-resolution surface temperature and rainfall analysis data from IMD. The temperature data was constructed by IMD based on 395 station observatories data at $1^{\circ} \times 1^{\circ}$ spatial resolution [66] covering the land region of India $\left(6.5^{\circ} \mathrm{N}-38.5^{\circ} \mathrm{N}, 66.5^{\circ} \mathrm{E}-100^{\circ} \mathrm{E}\right)$. Similarly, the rainfall data was prepared by IMD by considering the daily rainfall measurements from 6955 rain gauge stations at $0.25^{\circ} \times 0.25^{\circ}$ spatial grid [67]. These datasets are the finest observation data from IMD so far which 
use the highest number of station observations and are successfully utilized in various observation/modeling studies.

RegCM4 was initialized here with ESA-CCI soil moisture datasets (v.02.2). This dataset is a multi-decadal satellite-derived soil moisture product with high spatial resolution at $0.25^{\circ} \times 0.25^{\circ}$. The primary data is accumulated through various spaceborne microwave scatterometers, such as ERS-1/2 (SCAT) and METOP-A (ASCAT), as well as microwave radiometers, viz., SMMR, SSM/I, TMI, AMSR-E, WindSat and AMSR2. The detailed information about the different satellite sensors and their specification is mentioned in Dorigo et al. [61,62]. ESA provides three types of soil moisture products, viz., active only, passive only and combined datasets based on these gathered data. Active only data is made by merging all the data from the scatterometers while the passive only product is generated by merging all the data from radiometers. Afterwards these two products are further rescaled to the common platform of Global Land Data Assimilation System version-1 and merged to prepare the combined soil moisture data [68]. Complete procedural technique and further details about this data preparation may be obtained from the literature cited above and the references therein. The datasets are available in the volumetric unit $\left(\mathrm{m}^{3} \mathrm{~m}^{-3}\right)$ at daily scale during 1979-2014. The soil depth of the data varies in the range of $0.5-2 \mathrm{~cm}$. For this study, we used the ESA-CCI combined soil moisture data only. The ESA-CCI dataset are the calibrated data prepared with in situ observation from International Soil Moisture Network (ISMN; [62]). At present, ISMN data consists of 6100 soil moisture datasets from 1400 measurement stations operated by 40 different networks [62]. ISMN holds data globally having 10 station data in India. Validation is carried out for 28 data networks all over the globe. Detailed validation strategy including precise information about the measurement stations is mentioned in Dorigo et al. [62].

\subsection{Validation Strategy}

Model performance was assessed in terms of the spatiotemporal distribution of surface temperature, soil moisture and rainfall considering all India (AI henceforth) as well as its five homogeneous regions, viz., north west India, west central India, central and north-east India, south peninsular India and north east India (NWI, WCI, CNEI, SPI, NEI henceforth) [69]. The simulation forced with a default soil moisture lookup table (ESA-CCI) will be referred to as default (ESA) hereafter. The validation includes some of the basic inferential statistics such as mean, standard deviation (SD) and correlation. In order to further estimate the model ability in predicting the rainfall, equitable threat score (ETS) was computed. ETS is an ability measure generally used for dichotomous (yes/no) forecasting events [70,71]. Mathematically, ETS is defined as follows:

$$
E T S=\frac{H-H_{\text {rand }}}{H+M+F-H_{\text {rand }}}
$$

where

$$
H_{\text {rand }}=\frac{(H+M)(H+F)}{T}
$$

$H, M$ and $F$ stands for number of hits, misses and false alarms while $T$ and $H_{\text {rand }}$ refer to the total events and hits due to random chances, respectively. These values are calculated based on a $2 \times 2$ contingency table. ETS measures the fraction of perfectly forecast points, corrected using hits due to random chance. It varies in the range of $-1 / 3$ to 1 with ETS $\leq 0$ indicating no ability and ETS $=1$ indicating perfect ability.

\section{Results}

\subsection{Surface Temperature}

The analysis was started with the discussion about the model simulated surface temperature and its validation with the IMD observation. Results from 2002 (2011) are given in Figure 2 (Figure 3). The first two columns represent bias with default and ESA configuration with their difference in the last column. The first four rows $(a-c, d-f, g-i$, 
$\mathrm{j}-1)$ correspond to June, July, August and September while the last row (m-o) stands for seasonal (June-July-August-September; JJAS hereafter) mean. It indicates that RegCM4 showed consistent cold bias over peninsular India, irrespective of the years and attained maxima in July 2002 (Figure 2) and June 2011 (Figure 3). In contrast to the JJAS mean, it was noticed that the model exhibited cold (warm) bias during 2002 (2011) over north India. In the monthly distribution, RegCM4 experienced warm bias in August and September during 2002 while in July, August and September during 2011. The simulated surface temperature was noticed to be closer to IMD data when initialized with ESA soil moisture data. It indicates that the model was responsive to the soil moisture initialization process and outperformed after being initialized with real-time soil moisture data by reducing existing cold bias in the default soil moisture combination. The present model bias (cold/warm) might be associated with the simulation of rainfall by the model. We have discussed it in later subsections, particularly the model inefficiency in predicting various epochs of rainfall (during initial months of ISM) which might have possible consequences of obtaining different surface temperature biases.

A discussion was further extended by analyzing the daily variation of surface temperature. Time series of surface temperature during 2002 and 2011 over AI and its five homogeneous regions are described in Figures 4 and 5, respectively. Irrespective of the regions, temporal variation of surface temperature was estimated slightly better by the model when initialized with the ESA soil moisture data except for some evident exceptions. As observed earlier, the model showed consistent cold bias throughout the season in both the years over SPI, NEI as well as AI level. Underestimation was higher over SPI and AI compared to NEI. However, the temporal variation was not well simulated by the model. The model's ability was further investigated through different temporal statistics. Temporal correlation and standard deviation over AI and five homogeneous regions during 2002 and 2011 are illustrated in Table 2. Except for SPI, the model showed a significant correlation with the configuration (default and ESA) in both years. Even though minor variations at the regional scale existed, RegCM4 exhibited slightly better ability at the AI level with ESA configuration. Interestingly, the correlation was consistently highest over NWI in both the configuration and the years, which indicated the daily variation of surface temperature was simulated relatively better there. The table also noticed that the spread of surface temperature in ESA simulation was slightly higher in both the years. Overall, it concluded that soil moisture initialization in RegCM4 has a significant impact in simulating surface temperature and subsequently spatiotemporal distribution of surface temperature in individual month and season are better predicted by the model when initialized with realistic soil moisture data from ESA-CCI, albeit having few lacunae.

Table 2. Temporal statistics of surface temperature $\left({ }^{\circ} \mathrm{C}\right)$ from default, ESA configuration and IMD data over the whole of India and five homogeneous regions for the years 2002 and 2011. *: significant at $95 \%$ and $t$ : not significant at $95 \%$.

\begin{tabular}{ccccccccccc}
\hline \multicolumn{1}{c}{2002} \\
\hline & \multicolumn{2}{c}{ Correlation } & \multicolumn{2}{c}{ Standard Deviation } & \multicolumn{2}{c}{ Correlation } & \multicolumn{2}{c}{ Standard Deviation } \\
\hline & Default & ESASM & Default & ESASM & IMD & Default & ESASM & Default & ESASM & IMD \\
\hline NWI & $0.52^{*}$ & $0.48^{*}$ & 1.95 & 2.20 & 2.03 & $0.59 *$ & $0.54^{*}$ & 1.66 & 1.72 & 2.05 \\
WCI & $0.34^{*}$ & $0.39^{*}$ & 1.33 & 1.34 & 2.09 & $0.31^{*}$ & $0.50^{*}$ & 1.20 & 1.16 & 1.56 \\
CNEI & $0.42^{*}$ & $0.43^{*}$ & 1.84 & 1.94 & 1.81 & $0.32^{*}$ & $0.28^{*}$ & 1.33 & 1.17 & 1.33 \\
SPI & $-0.13^{+}$ & $0.03^{+}$ & 0.98 & 1.15 & 0.83 & $-0.10^{+}$ & $0.04^{+}$ & 0.75 & 0.78 & 0.74 \\
NEI & $0.46^{*}$ & $0.41^{*}$ & 1.62 & 1.58 & 0.78 & $0.38^{*}$ & $0.39^{*}$ & 1.06 & 1.06 & 0.83 \\
INDIA & $0.46^{*}$ & $0.49^{*}$ & 1.24 & 1.28 & 1.43 & $0.44^{*}$ & $0.47^{*}$ & 0.77 & 0.77 & 1.11 \\
\hline
\end{tabular}



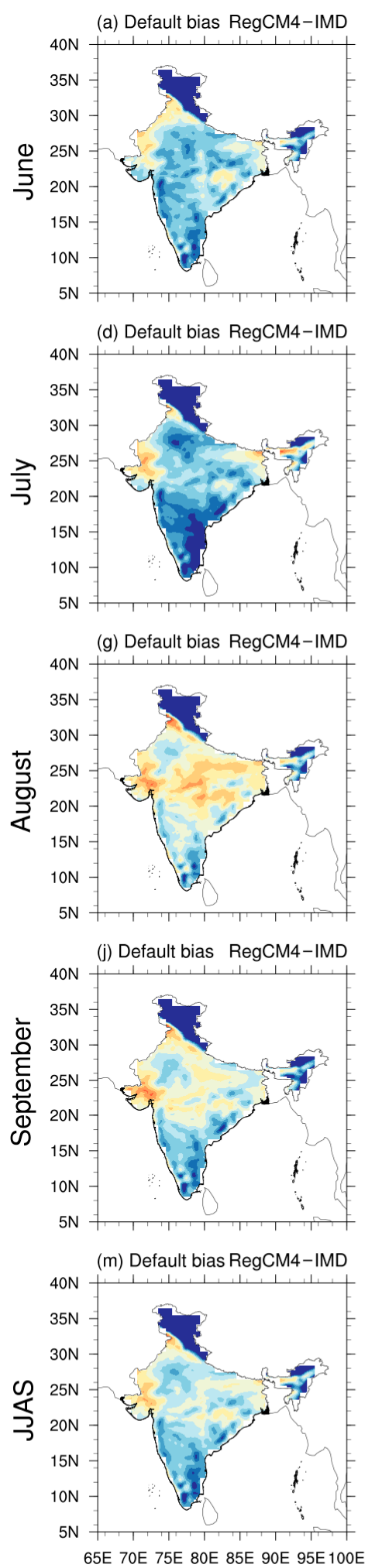

(b) ESA bias RegCM4-IMD

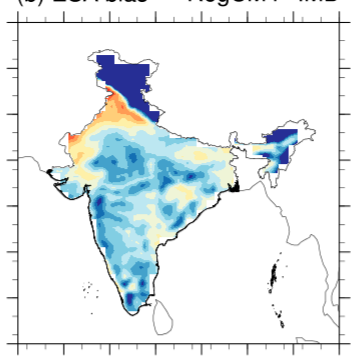

(e) ESA bias RegCM4-IMD

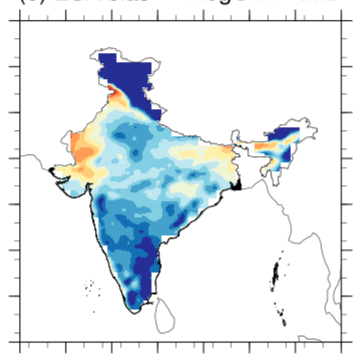

(h) ESA bias RegCM4-IMD
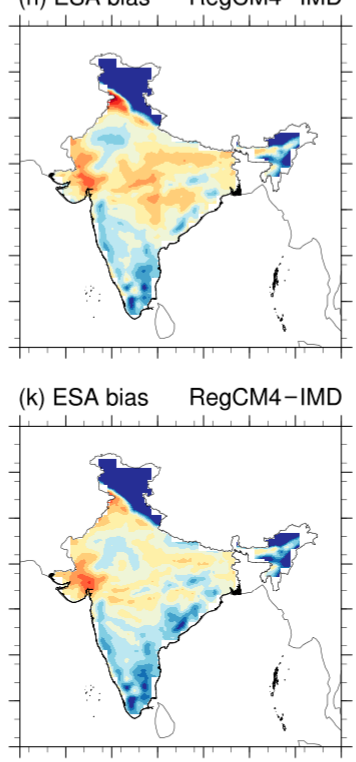

(n) ESA bias RegCM4-IMD

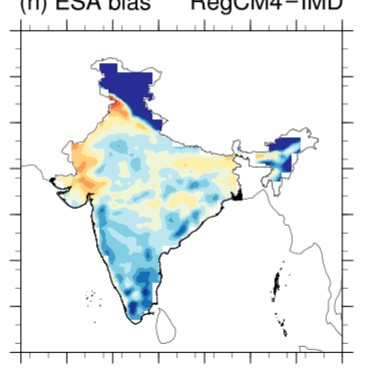

65E 70E 75E 80E 85E 90E 95E 100E

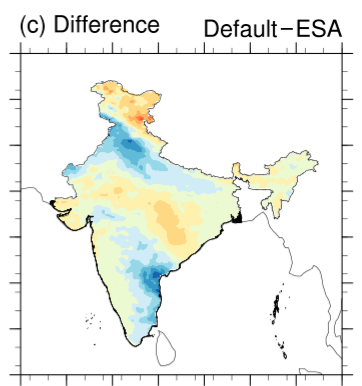

$\left({ }^{\circ} \mathrm{C}\right)$

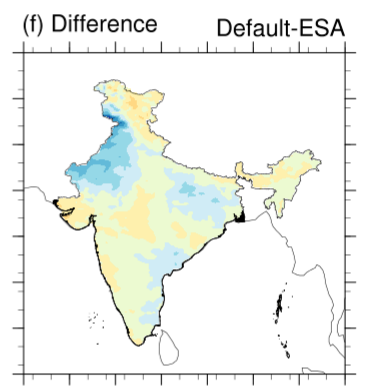

(i) Difference Default-ESA
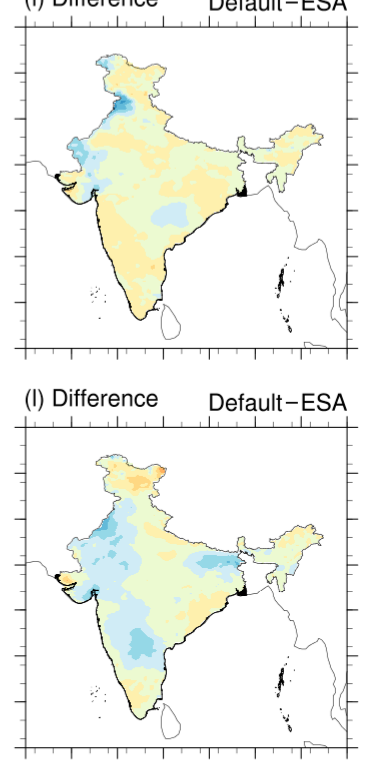

(o) Difference Default-ESA

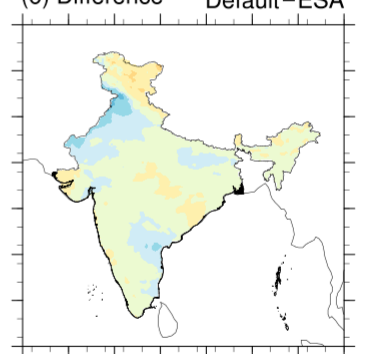

65E 70E 75E 80E 85E 90E 95E 100E

\section{$\begin{array}{llllllllll}-5 & -4 & -3 & -2 & -1 & 0 & 1 & 2 & 3 & 4\end{array}$}

$\left({ }^{\circ} \mathrm{C}\right)$

Figure 2. Surface temperature bias $\left({ }^{\circ} \mathrm{C}\right)$ at monthly and seasonal scales for the year 2002 from both the model configurations. IMD analysis is considered as ground truth. Rows correspond to (a-c) June, (d-f) July, (g-i) August, (j-1) September and $(\mathbf{m}-\mathbf{o})$ JJAS means. Columns represent the results from the default setup (1st column), ESA setup (2nd column) and their difference (3rd column). 

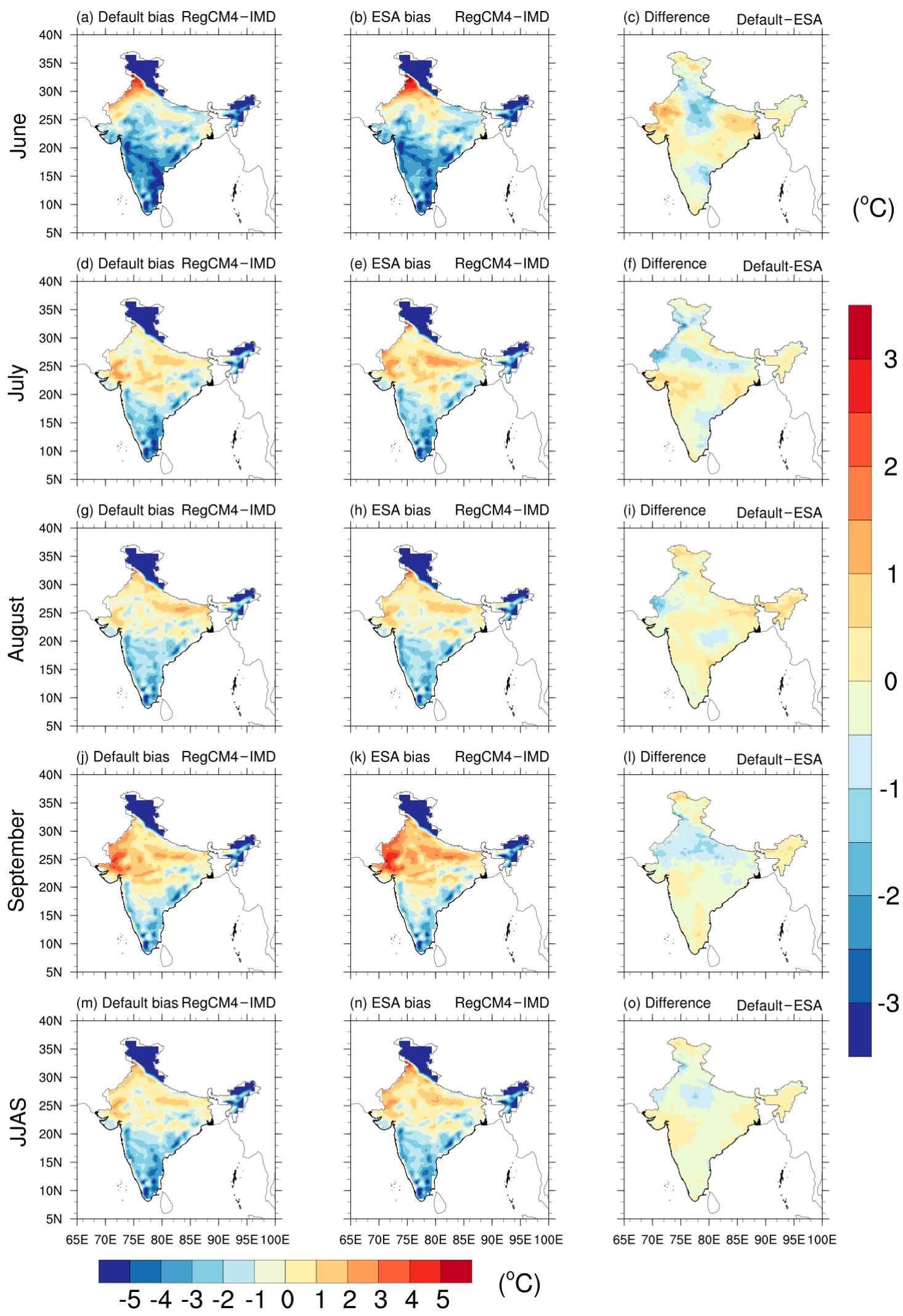

Figure 3. Same as Figure 2, but for the year 2011. 
(a) All India

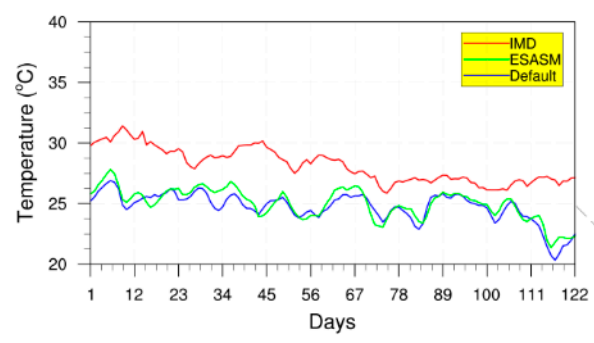

(b) North West India

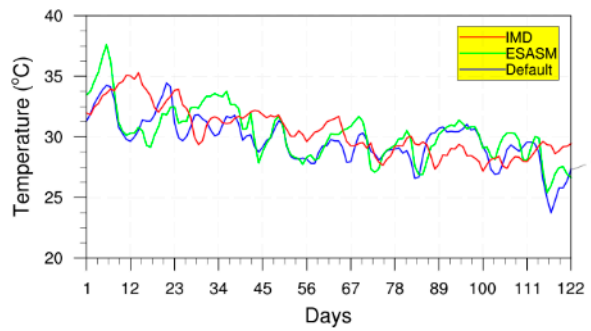

(c) West Central India

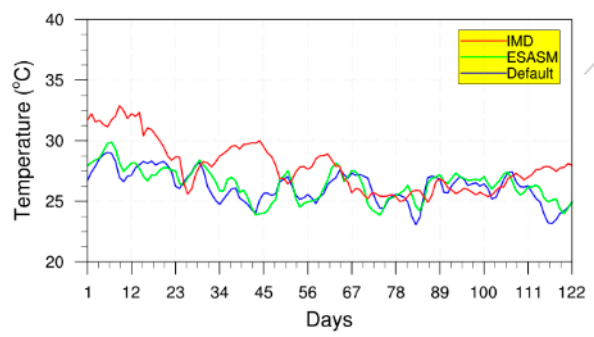

India
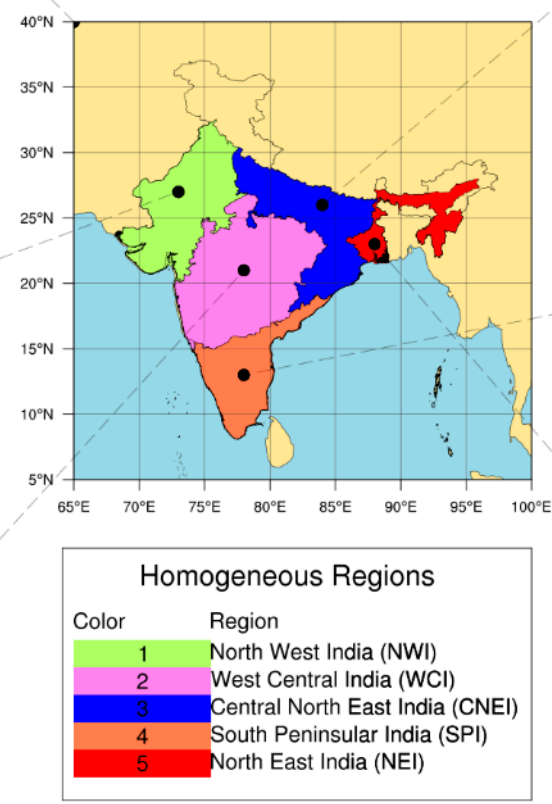

(d) Central North East India

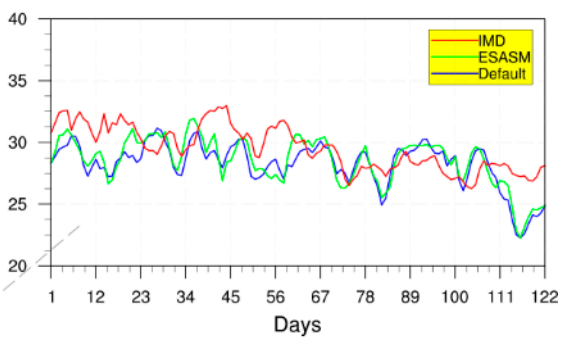

(e) South Peninsular India

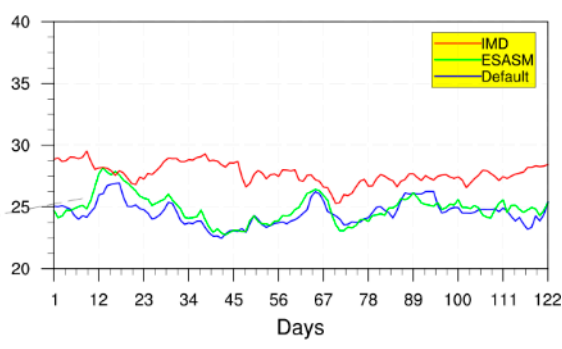

(f) North East India

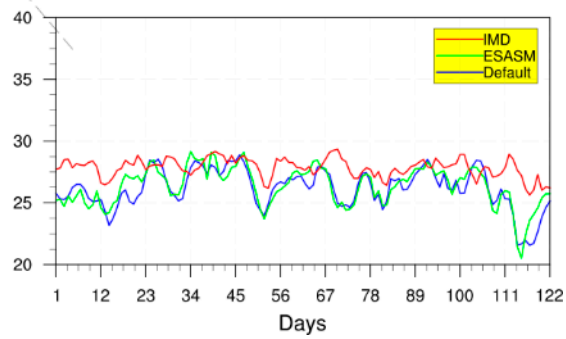

Figure 4. Daily variation of surface temperature $\left({ }^{\circ} \mathrm{C}\right)$ over $(\mathbf{a})$ India and $(\mathbf{b}-\mathbf{f})$ five homogeneous regions from the two setups (default, ESA) and IMD analysis for the year 2002. 
(a) All India

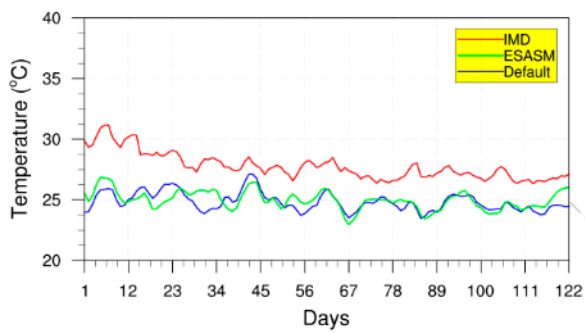

(b) North West India

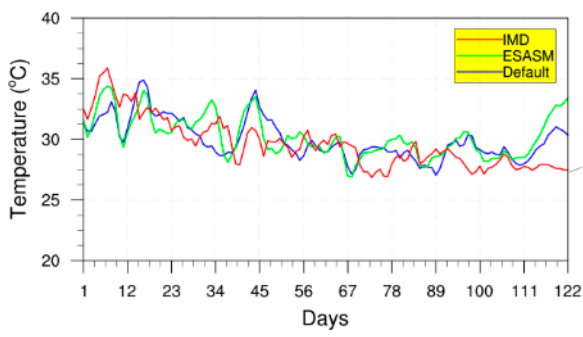

(c) West Central India

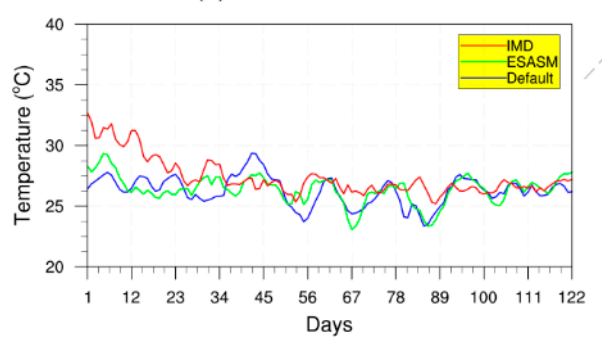

India
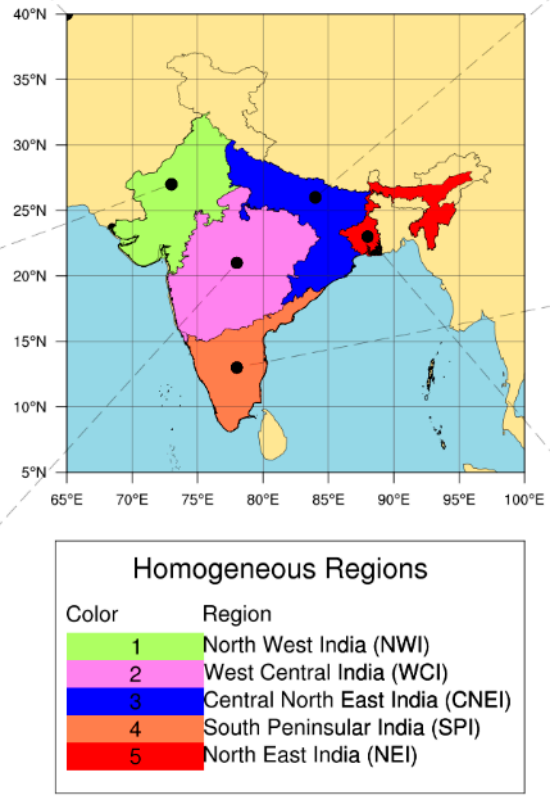

(d) Central North East India

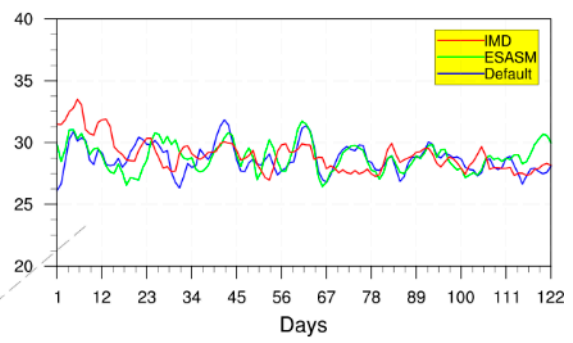

(e) South Peninsular India

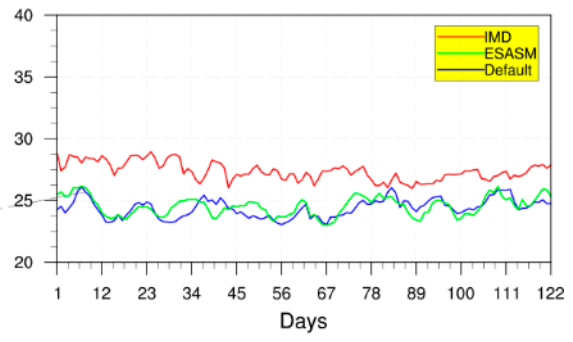

(f) North East India

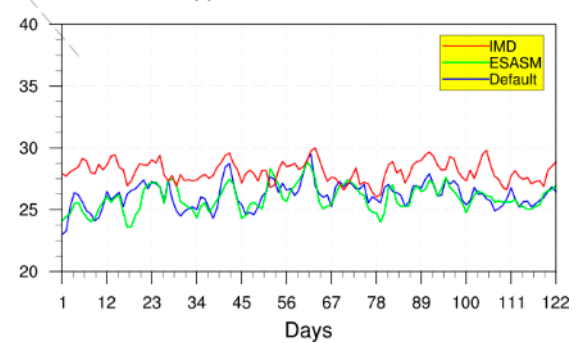

Figure 5. Same as Figure 4, but for the year 2011.

\subsection{Soil Moisture}

The model simulated seasonally averaged soil moisture from the two combinations (default and ESA) compared for 2002 and 2011 and validated with that from ESA-CCI (Figures 6 and 7). It is worth mentioning that RegCM4 provides soil moisture output in two layers, viz., upper/surface layer (with depth $10 \mathrm{~cm}$ ) and root zone layer (with depth $100 \mathrm{~cm}$ ). In this study, only upper layer soil moisture from the simulation and observation were considered for the model validation although they differ marginally in depth. While analyzing JJAS mean, it was observed that RegCM4 simulated the soil moisture reasonably well using both the setups. In both simulation and observation, soil moisture was found to vary in the range of $0.1-0.4 \mathrm{~m}^{3} \mathrm{~m}^{-3}$ over major parts of the Indian landmass. However, soil moisture was seen to be higher than that of ESA-CCI data in both combinations. 

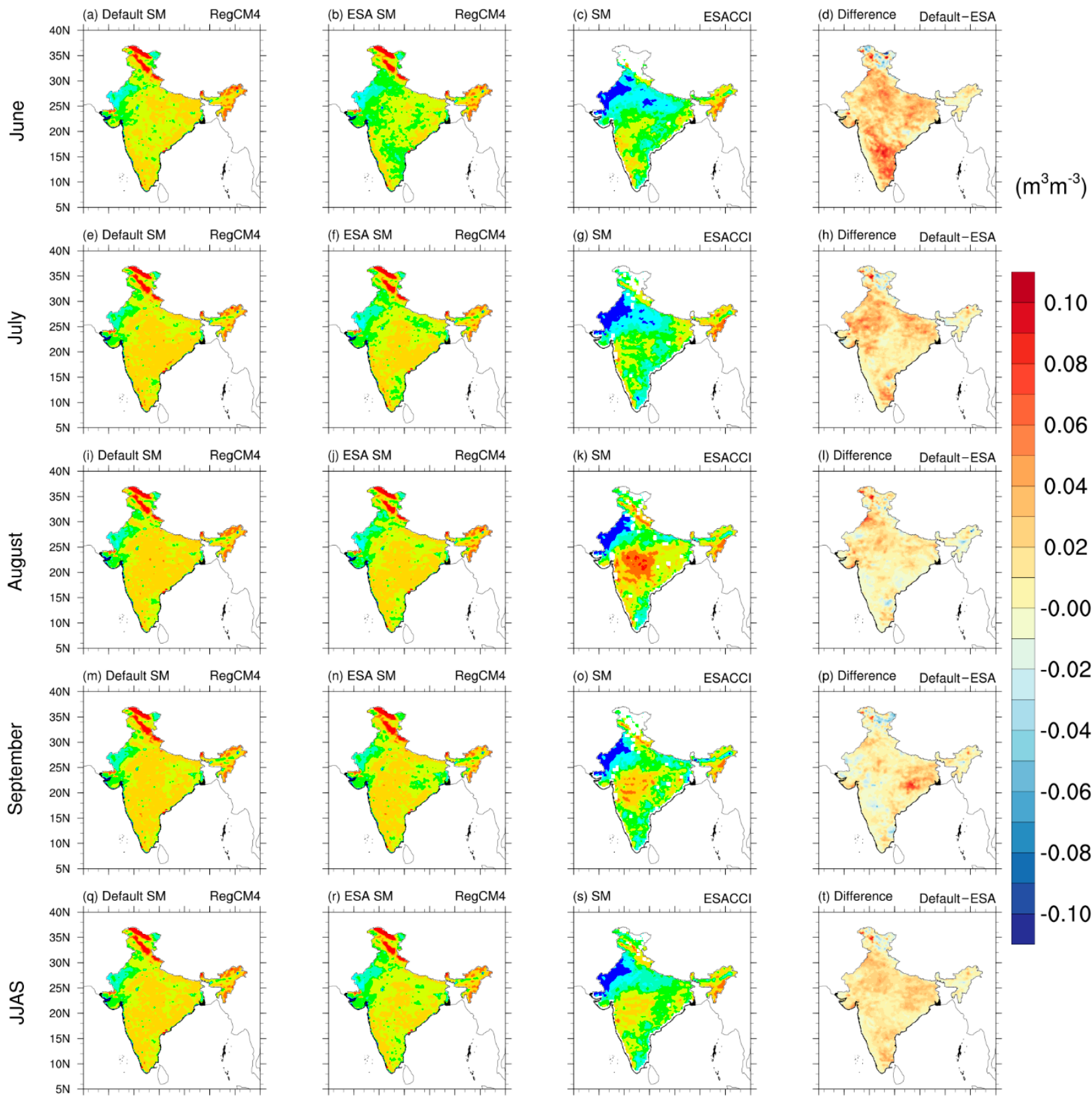

(r) ESA SM RegCM4
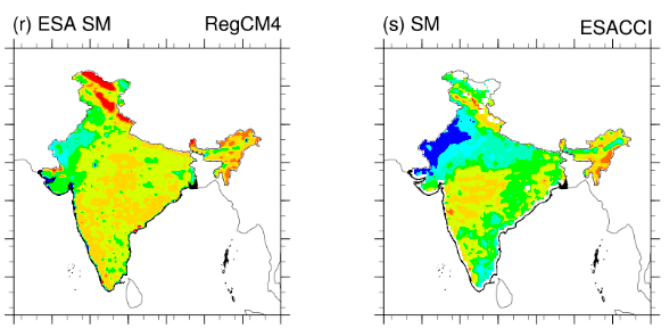

65E 70E 75E 80E 85E 90E 95E 100E

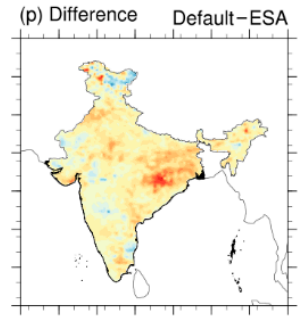

0.06

0.04

0.02

$-0.00$

65E 70E 75E 80E 85E 90E 95E 100 E

65E 70E 75E 80E 85E 90E 95E 100 E

(t) Difference Default-ESA

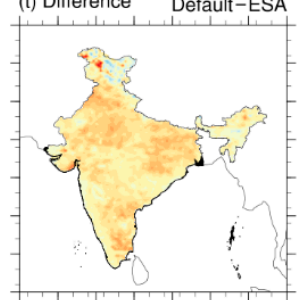

65E 70E 75E 80E 85E 90E 95E 100 E

\section{$\begin{array}{lllllll}0.10 & 0.15 & 0.20 & 0.25 & 0.30 & 0.35 & 0.40\end{array}$}

$\left(m^{3} m^{-3}\right)$

Figure 6. Soil moisture $\left(\mathrm{m}^{3} \mathrm{~m}^{-3}\right)$ at monthly and seasonal scale for the year 2002. Four columns represent simulated results from two setups, viz., default (1st column) and ESA (2nd column), ESA-CCI soil moisture (3rd column) and the difference from the two model setups (4th column). The five rows correspond with results for (a-d) June, (e-h) July, (i-l) August, $(\mathbf{m}-\mathbf{p})$ September and $(\mathbf{q}-\mathbf{t})$ JJAS means. 

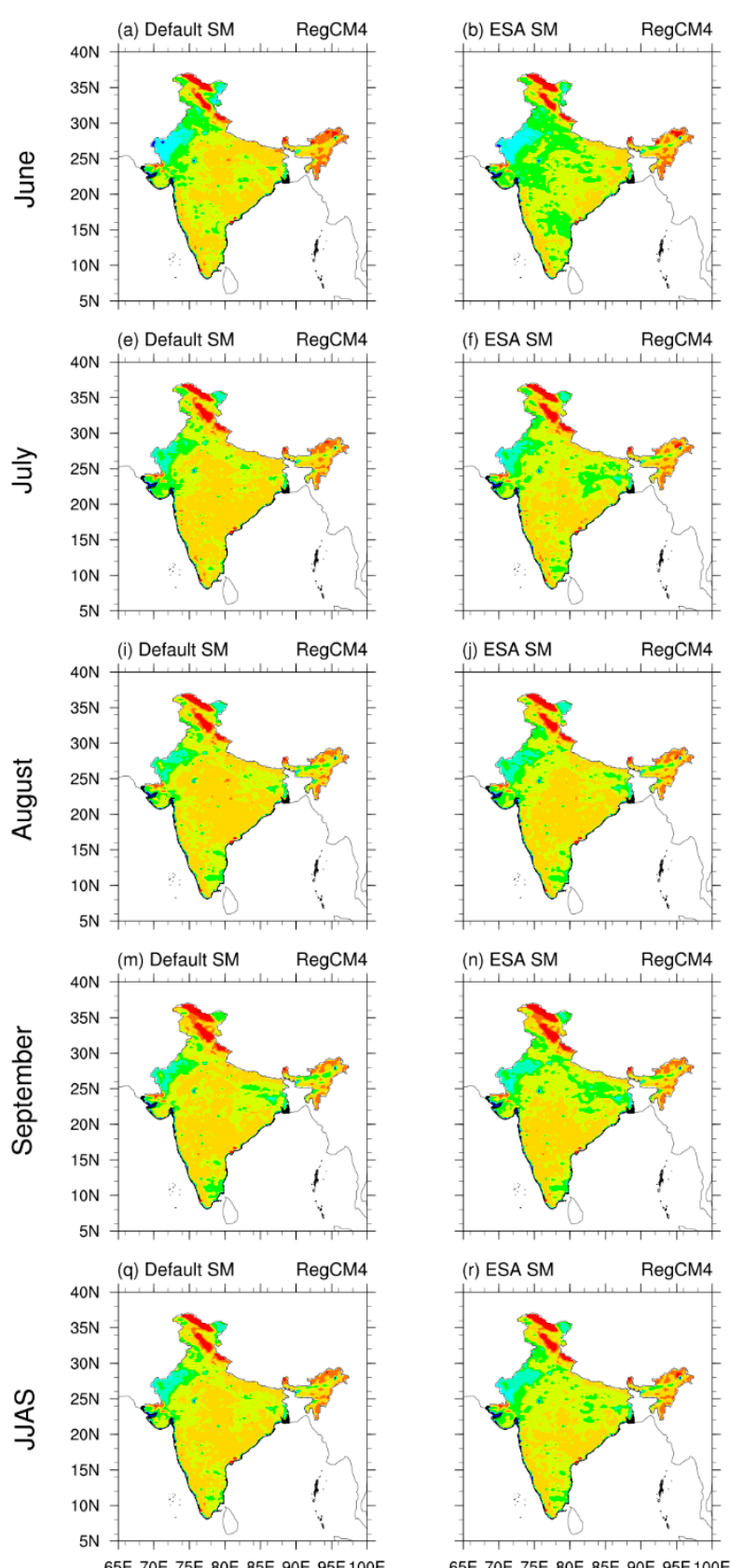
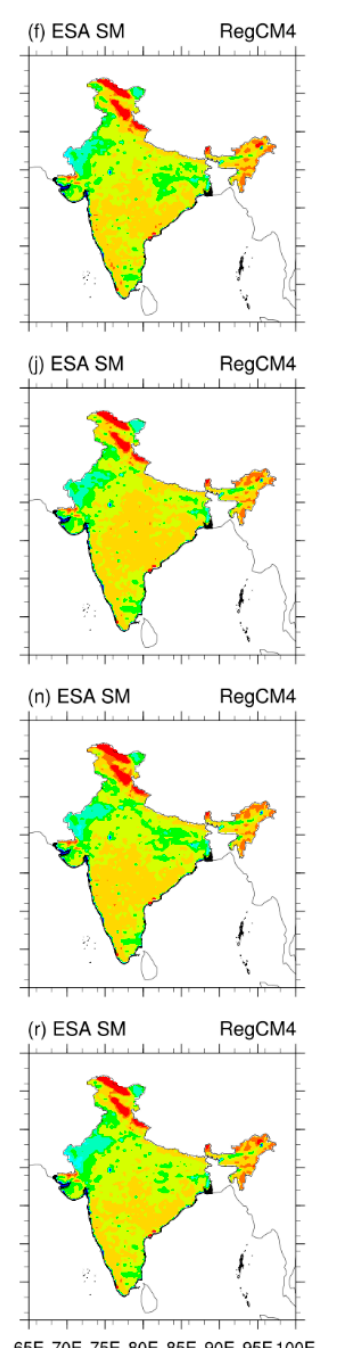

65E 70E 75E 80E 85E 90E 95E 100 E
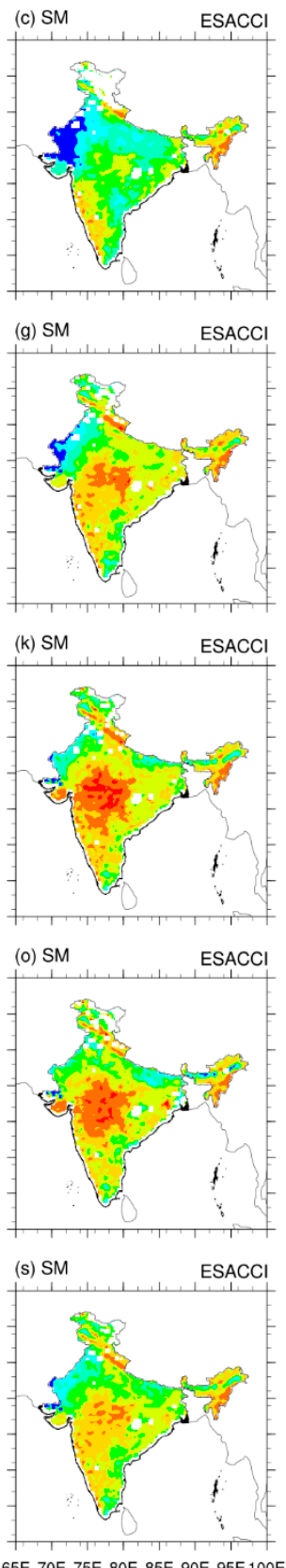

65E 70E 75E 80E 85E 90E 95E 100E

$\left(\mathrm{m}^{3} \mathrm{~m}^{-3}\right)$

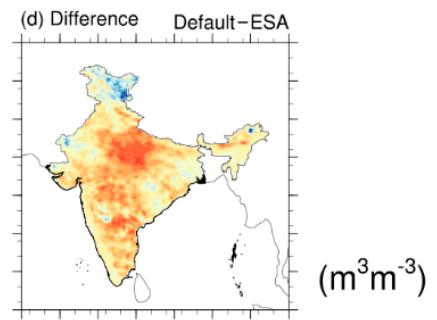

(h) Difference Default-ESA

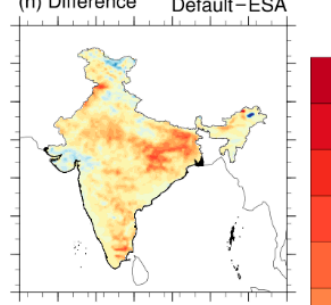

0.08

0.06

(l) Difference Default-ESA

0.04

0.02

$-0.00$

$-0.02$

(p) Difference Default-ESA

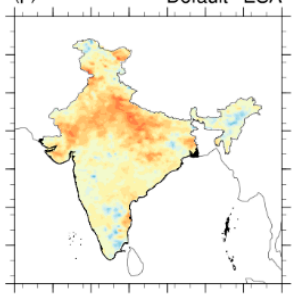

$-0.04$

$-0.06$

$-0.08$

(t) Difference Default-ESA

$-0.10$

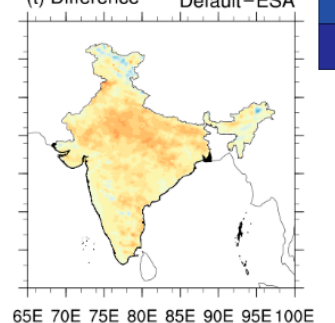

65E 70E 75E 80E 85E 90E 95E 100E

\section{$\begin{array}{lllllll}0.10 & 0.15 & 0.20 & 0.25 & 0.30 & 0.35 & 0.40\end{array}$}

Figure 7. Same as Figure 6, but for the year 2011.

For example, soil moisture over central India and the adjoining region was largely distributed in the range of $0.3-0.4 \mathrm{~m}^{3} \mathrm{~m}^{-3}$ in the model simulation, while ESA-CCI was found within $0.2-0.3 \mathrm{~m}^{3} \mathrm{~m}^{-3}$. Similarly, over western India and neighboring areas, the magnitude of simulated soil moisture was found in the range of $0.1-0.3 \mathrm{~m}^{3} \mathrm{~m}^{-3}$ but it varied within $0.1-0.2 \mathrm{~m}^{3} \mathrm{~m}^{-3}$ or even less in ESA-CCI. This disagreement was significantly noticed in 2002 (deficit year) compared to 2011 (normal year). As described earlier, the top soil layer in the model was deeper than that of ESA-CCI. Therefore, higher soil moisture in the model simulation may be attributed to this disparity in soil depth. Interestingly, soil moisture from the ESA setup was found to be more realistic in terms of spatial distribution. Soil moisture with default setup was considerably higher than using ESA data in both years and it was very prominent over central India and adjoining regions. Hence, it can 
be concluded that RegCM4 was appropriate for the soil moisture initialization technique. Moreover, while initialized with ESA-CCI data, the model improved the soil moisture distribution by reducing the non-realistic bias from the default setup.

The analysis was further extended by analyzing monthly soil moisture (June, July, August and September). As observed seasonally, simulated soil moisture was distinctly higher than that of ESA-CCI data on a monthly scale as well. It was noticed that ESA-CCI soil moisture was lower in June and it gradually improved in the months of July, August and September. The highest amount of soil moisture was noticed during August in both the years. Comparing both simulations, RegCM4 with default setup overestimated the soil moisture in each of the months. Consequently, soil moisture from ESA configuration was more realistic and hence closer to ESA-CCI. These differences were strongly visible from their differences indicated in the last column of Figures 6 and 7 which was noted to be highest in June and lowest in August. Hence, based on the above analysis, it is concluded that RegCM4 was extremely sensitive to the soil moisture initialization. Therefore, RegCM4 using the ESA setup showed reasonable enhancement in soil moisture simulation.

\subsection{Rainfall}

In order to investigate the impact of soil moisture initialization on rainfall, model simulated rainfall was analyzed in different spatiotemporal scale. Daily, monthly and seasonal rainfalls from the model simulation were compared with IMD over AI and five homogeneous regions (mentioned earlier). The monthly and seasonal rainfall (mmday ${ }^{-1}$ ) distribution from the two model combinations during 2002 and 2011 is illustrated in Figures 8 and 9, respectively, in terms of bias and individual difference. From the JJAS mean (last row of the figures), the model depicted wet bias over western and peninsular India and dry bias over NEI including Gangetic West Bengal and the west coast. Wet bias was higher in 2002 (deficit) while the dry bias was stronger in 2011 (normal). Central India experienced predominantly wet bias in 2002 and dry bias in 2011. These disparities in biases might be related to the model's ability in accurately predicting intraseasonal variation of rainfall (discussed later). 

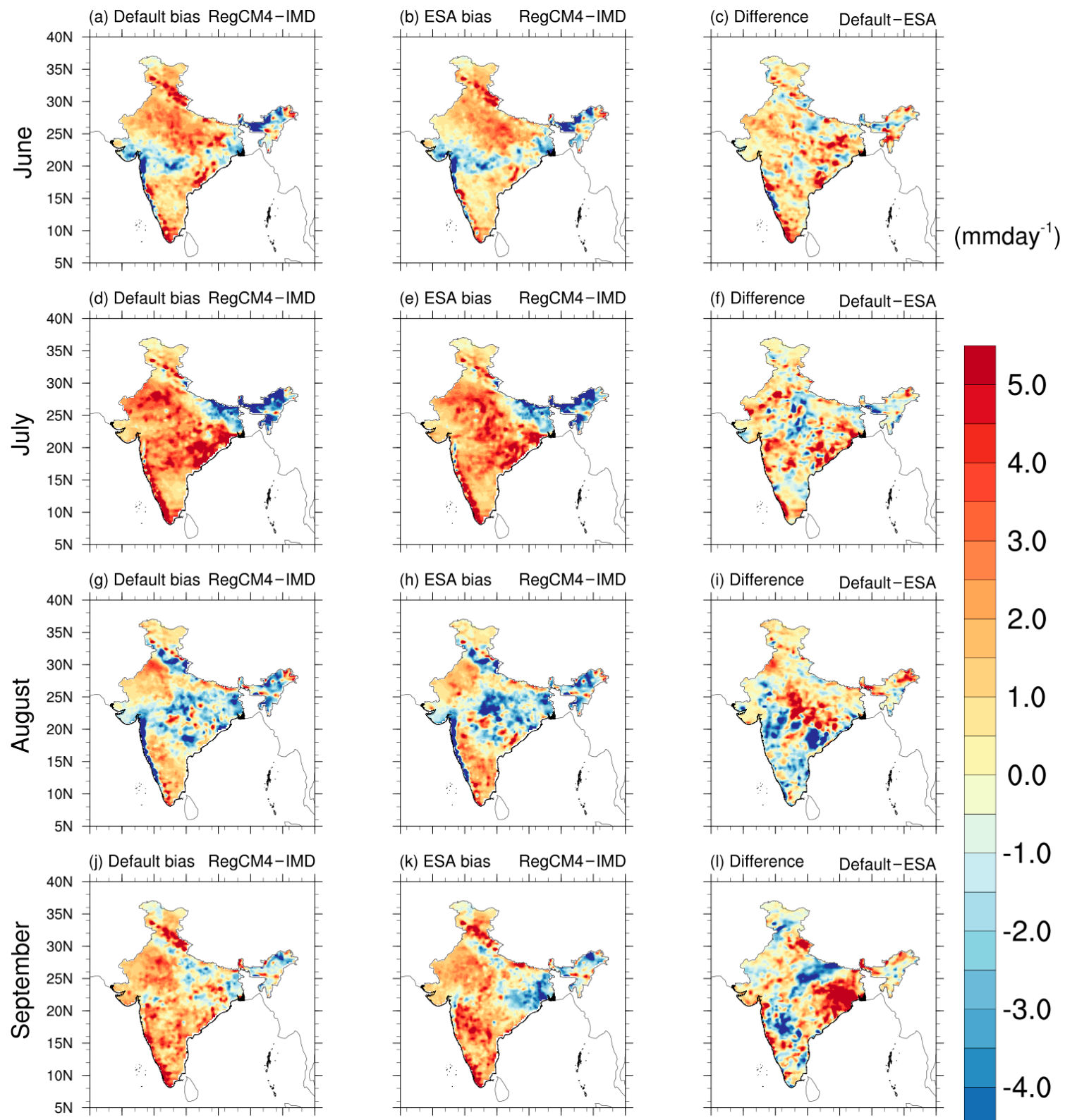

$-1.0$

2.0

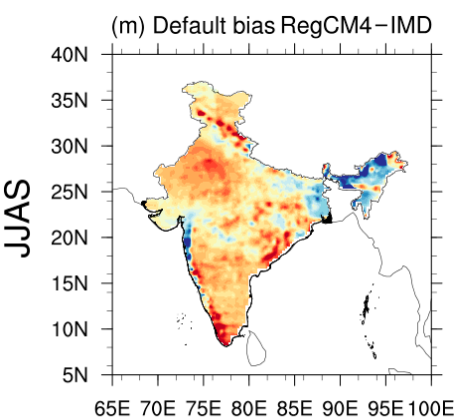

(n) ESA bias RegCM4-IMD
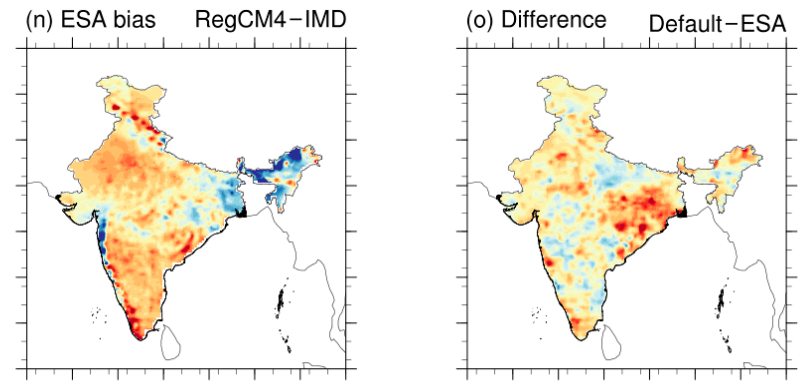

65E 70E 75E 80E 85E 90E 95E 100E

65E 70E 75E 80E 85E 90E 95E 100E

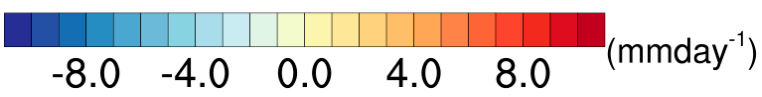

Figure 8. Rainfall bias $\left(\mathrm{mmday}^{-1}\right)$ at monthly and seasonal scales for the year 2002 from both the model configuration. IMD analysis is considered as ground truth. Rows correspond to (a-c) June, (d-f) July, (g-i) August, (j-1) September and $(\mathbf{m}-\mathbf{o})$ JJAS means. Columns represent the results from the default setup (1st column), ESA setup (2nd column) and their differences (3rd column). 

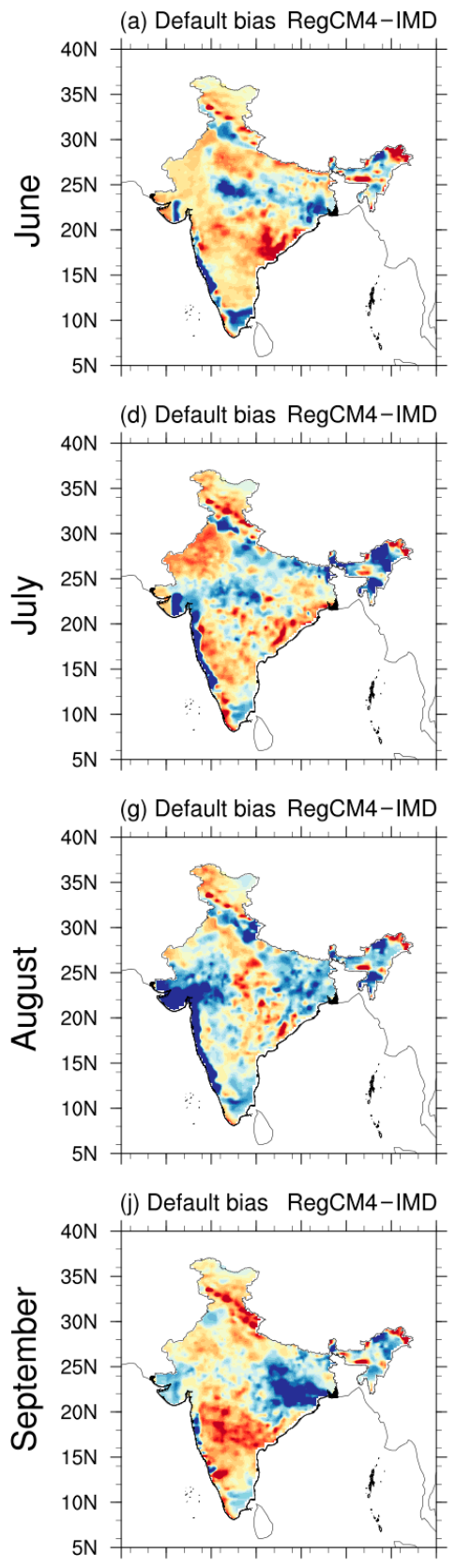

(m) Default bias RegCM4-IMD

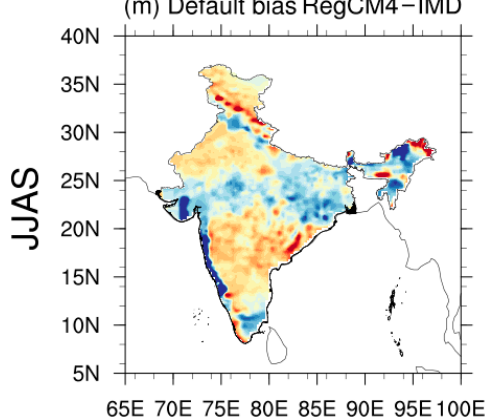

(b) ESA bias RegCM4-IMD

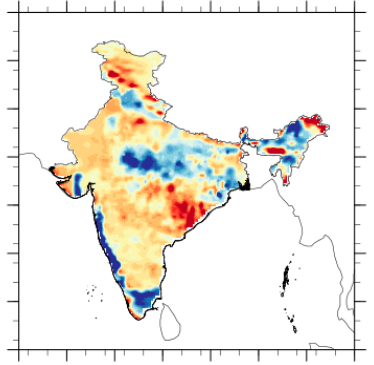

(e) ESA bias RegCM4-IMD

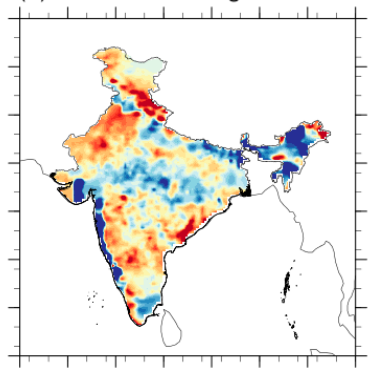

(h) ESA bias RegCM4-IMD

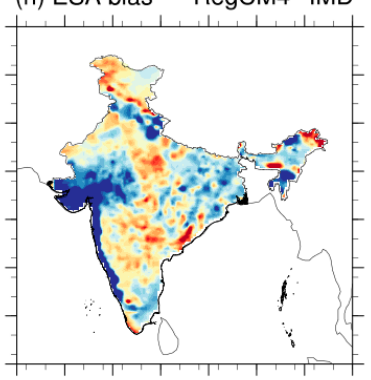

(k) ESA bias RegCM4-IMD

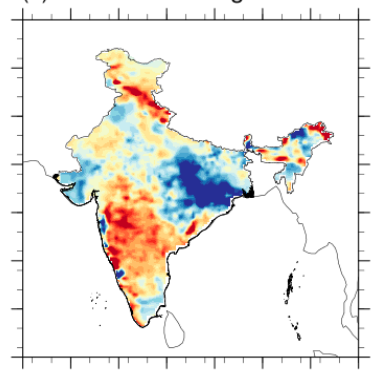

(n) ESA bias RegCM4-IMD

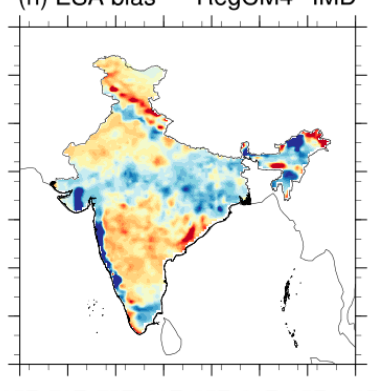

65E 70E 75E 80E 85E 90E 95E 100E (c) Difference Default-ESA

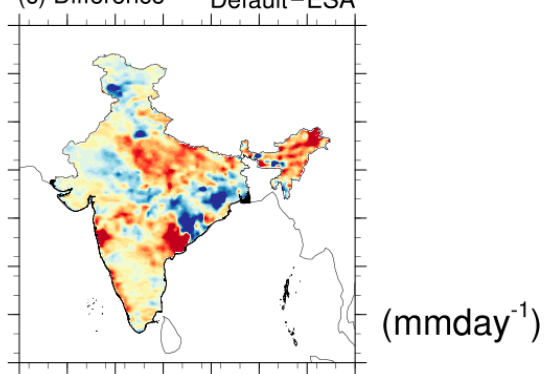

(f) Difference Default-ESA

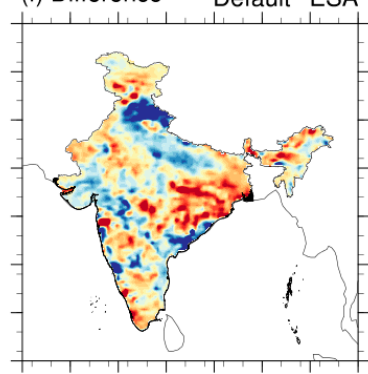

5.0

4.0

3.0

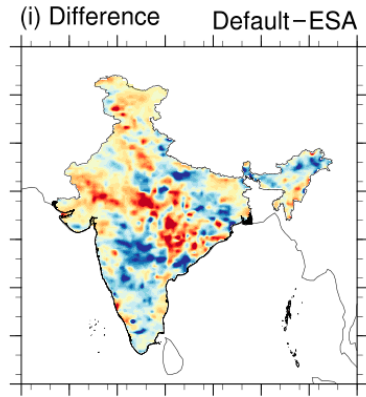

2.0

1.0

0.0

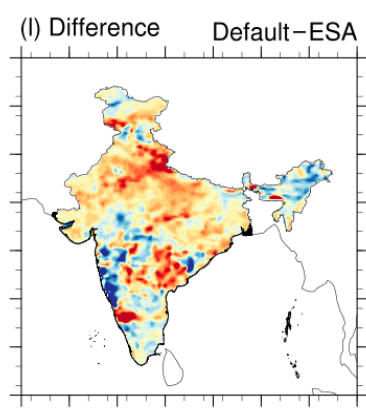

$-1.0$

$-3.0$

$-4.0$

(o) Difference Default-ESA

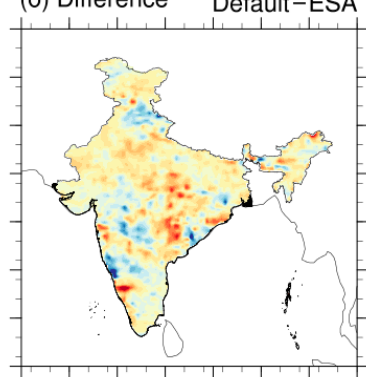

65E 70E 75E 80E 85E 90E 95E 100E

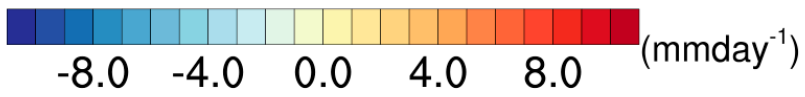

Figure 9. Same as Figure 8, but for the year 2011. 
The model simulated monthly rainfall (June, July, August and September) during 2002; 2011 was also analyzed (Figures 8 and 9) as a part of the validation. During June, July and September of 2002, the model showed wet bias over the major part of the Indian landmass except for NEI and Gangetic West Bengal where dry bias was noticed. Both the biases were found highest in July. Similarly, dry bias regions remained similarly visible in 2011 while the coverage of wet bias regions were reduced with lower magnitude, indicating an improvement in model ability. Nevertheless, it is important to mention that RegCM4 with ESA setup reduced the rainfall bias.

Day-to-day variation of rainfall is an important aspect of ISM which controls the overall performance of the model throughout the season. Hence, daily rainfall variations from the model simulation in both the years were examined over the whole of India and the other five regions against IMD observation (Figures 10 and 11). The rainfall was significantly overestimated (underestimated) over the majority of Indian land throughout the season in 2002 (2011) by the model, except for a few extreme epochs. Moreover, the variation within the season was also not reasonably well simulated by the model. During 2002, it was observed that rainfalls were not initiated on the same dates over all the homogeneous domains and rather maintained intervals of a few days.

(a) All India

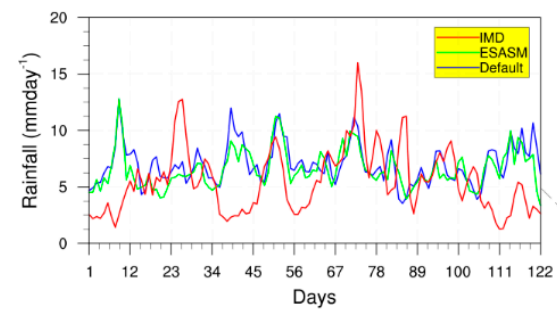

(b) North West India

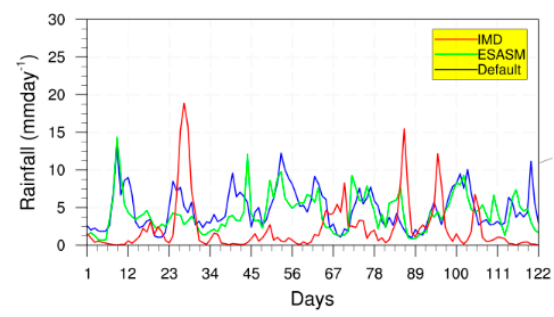

(c) West Central India

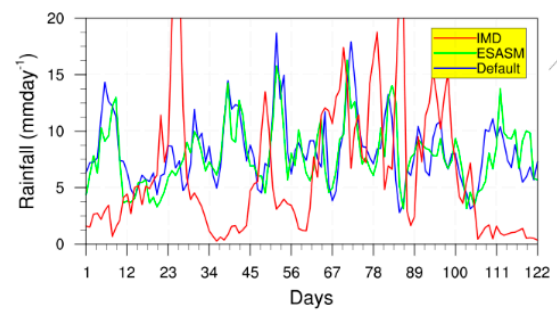

(d) Central North East India

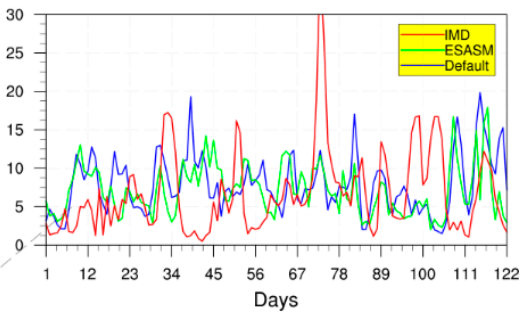

(e) South Peninsular India

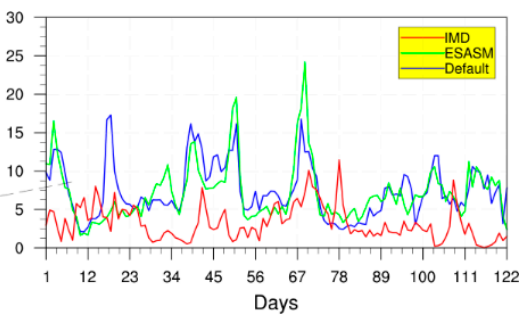

(f) North East India

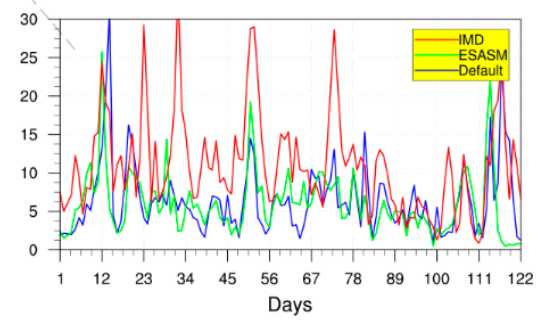

Figure 10. Daily variation of rainfall $\left(\mathrm{mmday}^{-1}\right)$ over $(\mathbf{a})$ India and $(\mathbf{b}-\mathbf{f})$ five homogeneous regions derived from the two setups (default, ESA) and IMD analysis for the year 2002. 
(a) All India

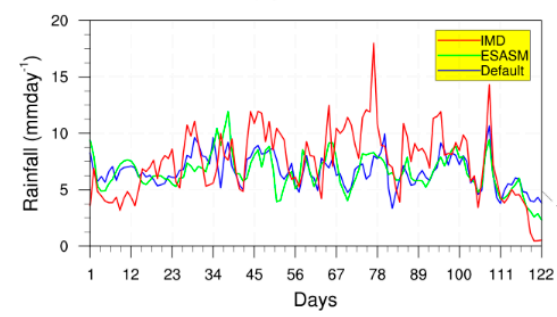

(b) North West India

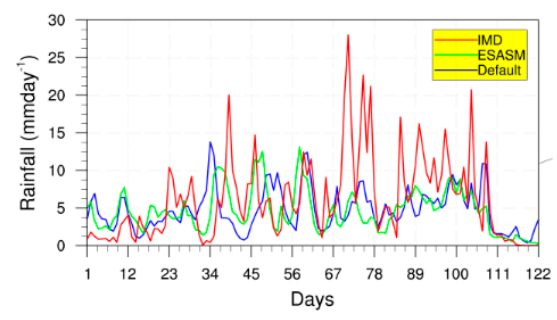

(c) West Central India

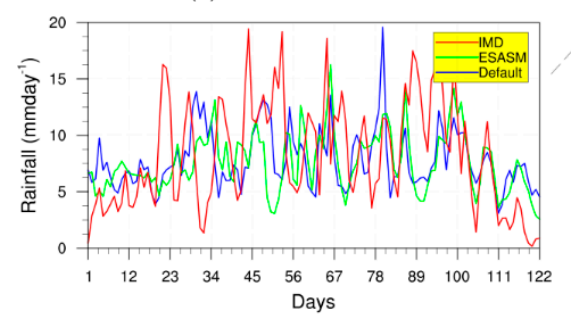

(d) Central North East India

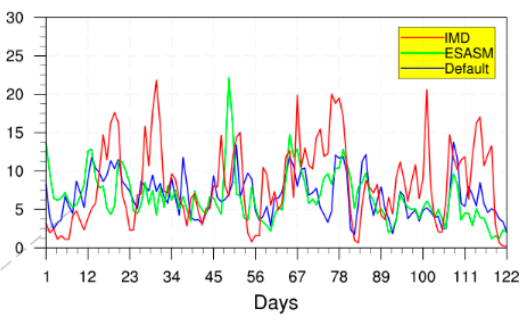

(e) South Peninsular India

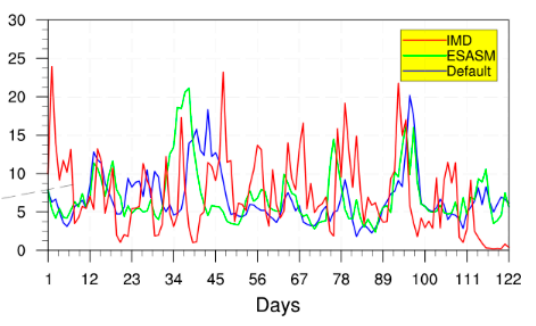

(f) North East India

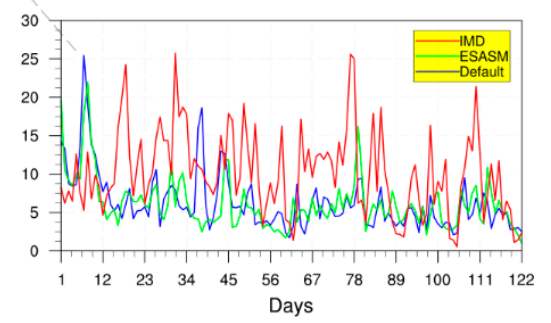

Figure 11. Same as Figure 10, but for the year 2011.

The first rainfall peak was noticed over SPI followed by WCI, NWI, CNEI and NEI. While similarly compared with IMD over the corresponding regions, it was noticed to be earlier by a few days in the model simulation. This indicated that the model showed early onset over each of the regions compared to the IMD data. Similarly, RegCM4 exhibited delayed withdrawals from each of the regions during the end of the season. In contrast with 2002, moderately better performance was perceived during 2011. Even though the model showed a large amplitude of over and underestimation during the peak rainfall months of July and August, it followed the daily rainfall pattern of IMD.

Interestingly, the onset and withdrawal of 2011 were also reasonably well simulated by the model. It implies that the model exhibited better ability during a normal monsoon year (2011) as compared to an extreme year (2002). Temporal statistics (correlation and standard deviation) for the two years are provided in Table 3. It shows a 95\% significant correlation during 2011 in both the simulation over major parts of India, and therefore, simulation using ESA soil moisture was slightly better in comparison to others. Contrarily, correlations were insignificant and negative over the whole of India in 2002, which indicated deviation in model ability. However, the standard deviation was significantly less than IMD, which inferred limited model performance regarding accurate prediction of magnitude. 
Table 3. Temporal rainfall statistics $\left(\mathrm{mmday}^{-1}\right)$ from default, ESA configuration and IMD data over the whole of India and five homogeneous regions for the years 2002 and 2011. *: significant at 95\%; t: not significant at $95 \%$.

\begin{tabular}{ccccccccccc}
\hline \multicolumn{9}{c}{2002} & \multicolumn{9}{c}{2011} \\
\hline & \multicolumn{3}{c}{ Correlation } & \multicolumn{2}{c}{ Standard Deviation } & \multicolumn{2}{c}{ Correlation } & \multicolumn{2}{c}{ Standard Deviation } \\
\hline & Default & ESASM & Default & ESASM & IMD & Default & ESASM & Default & ESASM & IMD \\
\hline NWI & $-0.14^{+}$ & $-0.14^{+}$ & 2.62 & 2.48 & 3.37 & $0.27^{*}$ & $0.38^{*}$ & 2.80 & 2.80 & 5.56 \\
WCI & $-0.14^{+}$ & $-0.12^{+}$ & 2.98 & 2.81 & 5.89 & $0.16^{+}$ & $0.22^{*}$ & 2.63 & 2.66 & 4.81 \\
CNEI & $-0.06^{+}$ & $-0.03^{+}$ & 3.77 & 3.29 & 5.62 & $0.41^{*}$ & $0.19^{*}$ & 2.83 & 3.29 & 5.29 \\
SPI & $-0.07^{+}$ & $-0.03^{+}$ & 3.52 & 3.77 & 2.24 & $0.02^{+}$ & $0.03^{+}$ & 3.39 & 3.69 & 5.11 \\
NEI & $0.40^{*}$ & $0.34^{*}$ & 4.67 & 4.12 & 6.41 & $0.11^{+}$ & $0.17^{+}$ & 3.74 & 3.43 & 5.49 \\
INDIA & $-0.04^{+}$ & $0.03^{+}$ & 1.77 & 1.70 & 2.86 & $0.51^{*}$ & $0.47^{*}$ & 1.43 & 1.64 & 2.99 \\
\hline
\end{tabular}

To investigate the model ability during extreme monsoon years, differences of seasonal average (2011-2002) of the three parameters (rainfall, surface temperature and soil moisture) were analyzed (Figure 12). It was noticed that soil moisture and rainfall were relatively higher during 2011 while the surface temperature was lower in 2011 (last row of Figure 12). Simulated results are depicted in the 1st and 2nd rows using the default and ESA setups. It was noticed that the spatial patterns in both the model combinations were not prominent while compared to observations. Moreover, simulated surface temperature over north India was slightly higher in 2011, contradicting observations. Even though RegCM4 with ESA setup improved the simulation by reducing bias, further enhancement is needed. There was hardly any difference between the two years with regard to soil moisture using both combinations. Surprisingly, the model showed mixed performance in simulating rainfall during the two years and therefore the results were not convincing. Hence, based on the above analysis, it is concluded that the contrasting monsoon features were not well captured by the model when compared to observations.

\subsection{Quantitative Evaluation: Equitable Threat Score}

In our study, ETS is computed over AI and five homogeneous regions (described earlier) for different rainfall categories $\left(0-5,5-10,10-20\right.$ and $20-50$ mmday $^{-1}$ during 2002 and 2011 and are illustrated in Figures 13 and 14, respectively. Higher ETS in 2011 (Figure 14) indicates that the precipitation events at an all-India level were better estimated by the model in 2011 compared to 2002 (Figure 13). Magnitude of ETS was relatively higher in ESA simulation for all rainfall categories in 2011, indicating improvement in rainfall simulation using ESA soil moisture.

Although RegCM4, with default setup, showed similar ability in higher rainfall category (10-20 and 20-50 mday $\left.^{-1}\right)$, its efficiency deviated in low $\left(0-5\right.$ mmday $\left.^{-1}\right)$ or moderate (5-10 mmday $^{-1}$ ) rainfall cases. At regional scale, highest ETS was noticed over NWI followed by CNEI, WCI, SPI and NEI. In 2011, the model with default configuration showed higher ETS in the low category rainfall over CNEI, WCI and SPI. Moderate rainfall was better estimated using the ESA setup. As observed earlier, ETS values were similar for both the setup in high rainfall cases indicating superior efficiency of the model in predicting high rainfall compared to other categories. During 2002, higher ETS was noticed in higher rainfall cases over NWI followed by AI but failed to estimate other categories. The model was unable to show any ability for other regions. It is noteworthy to mention that RegCM4 consistently showed better ability over NWI in estimating moderate/high rainfall events irrespective of the years. Performance of RegCM4 in 2011 (normal year) was better compared to 2002 (deficit year) and consequently exhibited superior ability in predicting all categories of rainfall while initialized with ESA soil moisture. 
(a) Raifnall

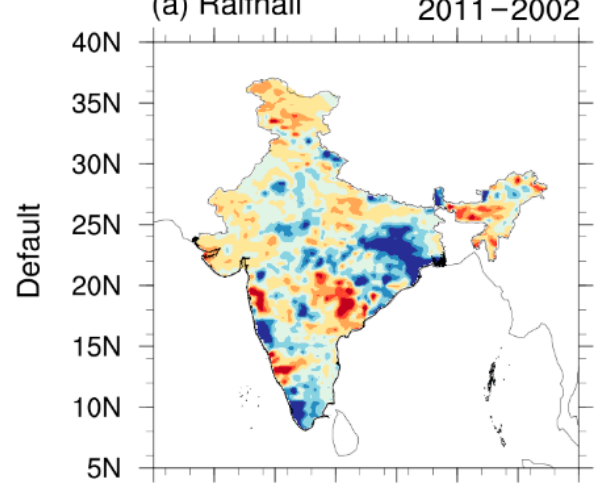

(d) Rainfall

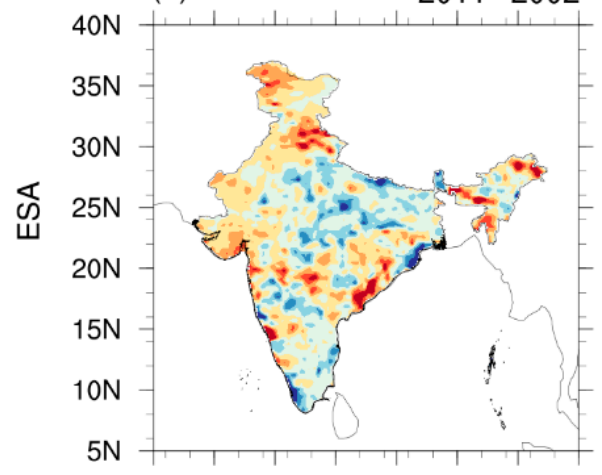

(g) Rainfall(IMD) 2011-2002

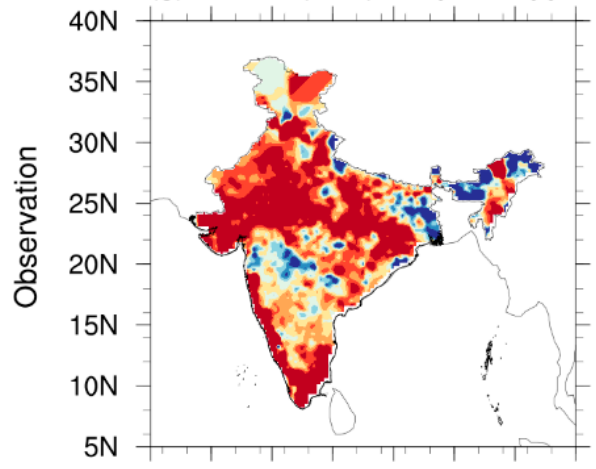

65E 70E 75E 80E 85E 90E 95E 100E

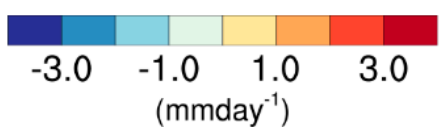

(b) Temp.

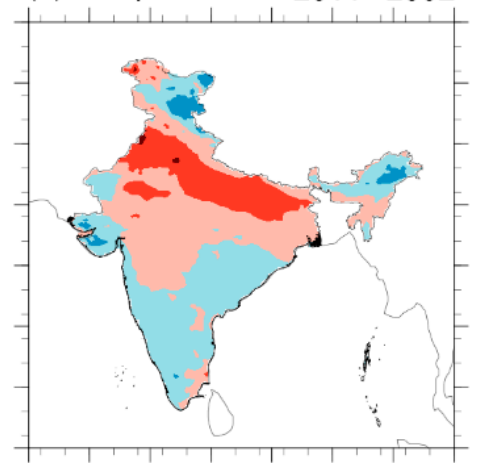

(e) Temp.

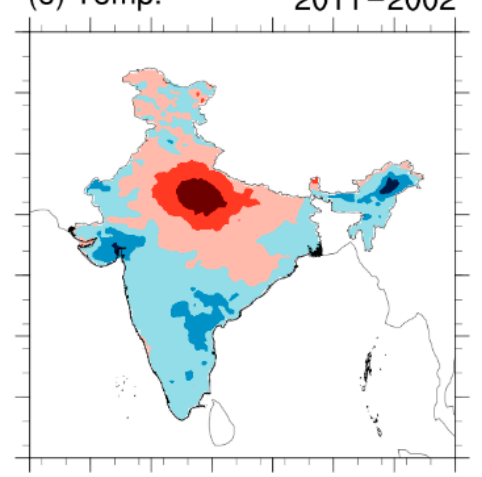

(h) Temp.(IMD)

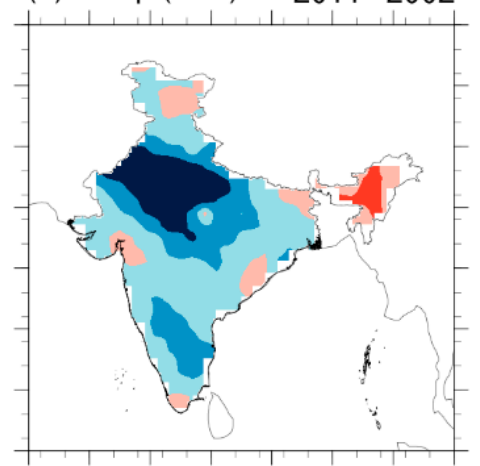

65E 70E 75E 80E 85E 90E 95E 100E

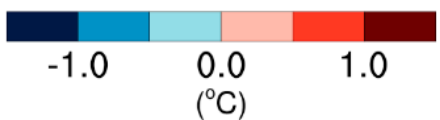

(c) Soil moist.

2011-2002

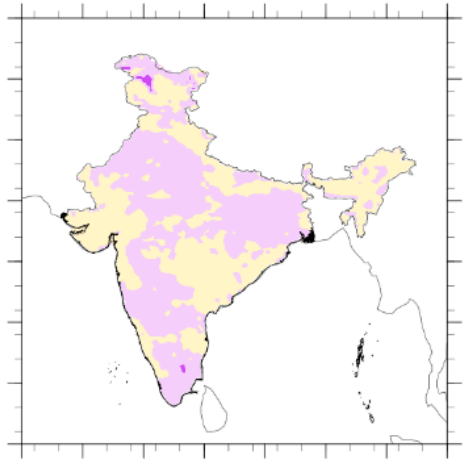

(f) Soil moist.

2011-2002

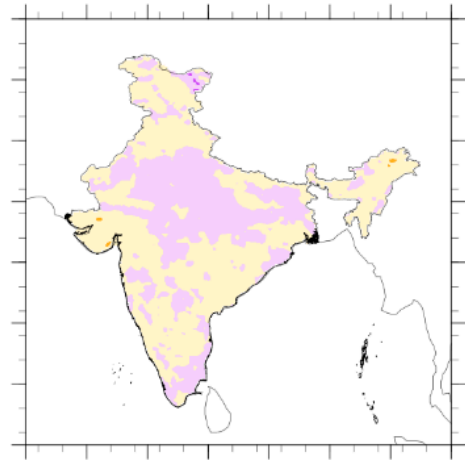

(i) Soil moist.(ESA) 2011-2002

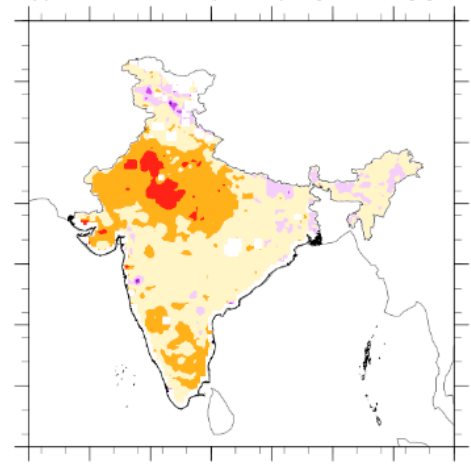

65E 70E 75E 80E 85E 90E 95E 100E

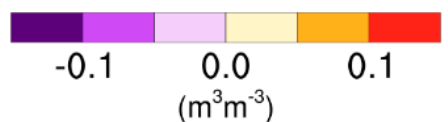

Figure 12. JJAS mean difference (2011-2002) of rainfall (1st column), surface temperature (2nd column) and soil moisture (3rd column). Rows represent the results from simulation with $(\mathbf{a}-\mathbf{c})$ default setup, $(\mathbf{d}-\mathbf{f})$ ESA setup and (g-i) observation. 
(a)

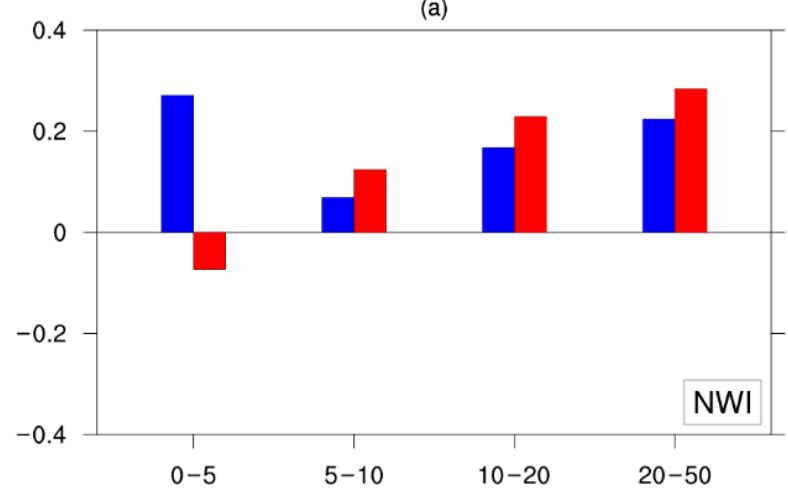

(c)

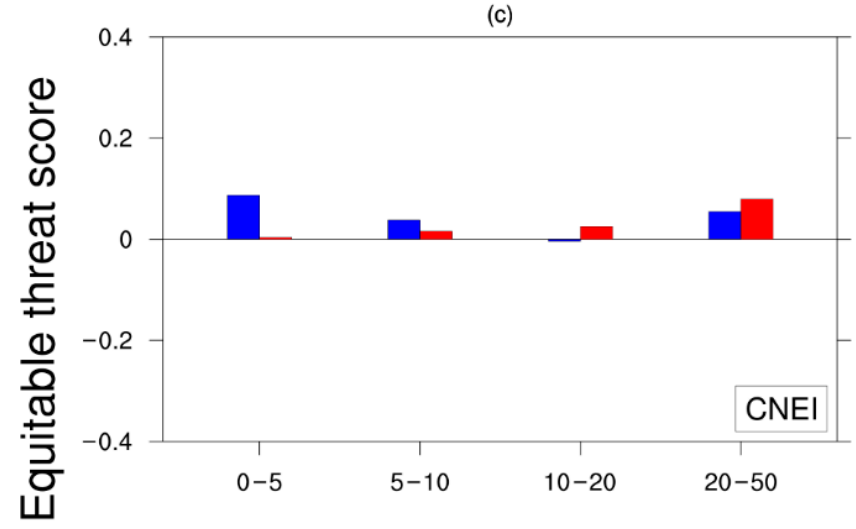

(e)

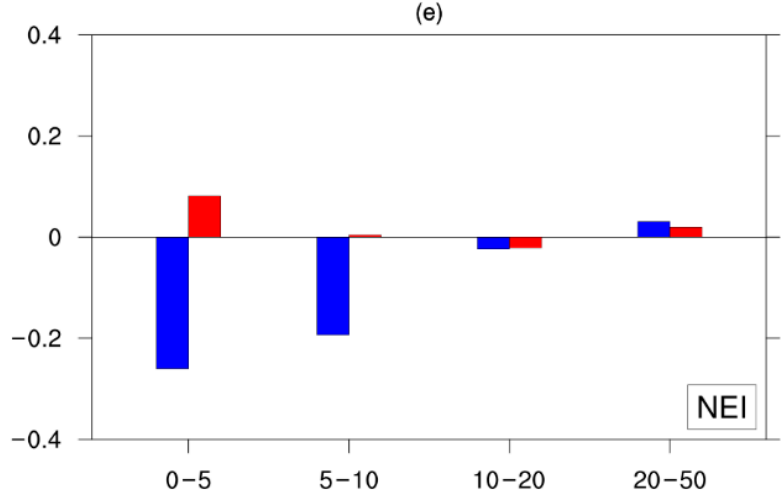

(b)

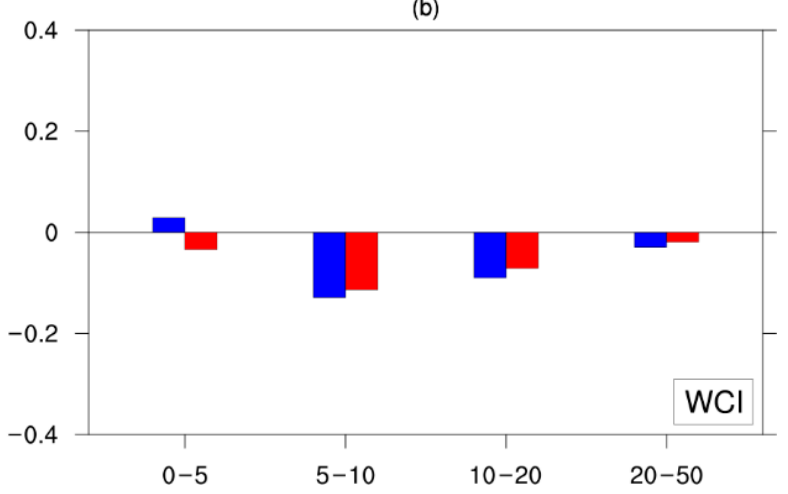

(d)

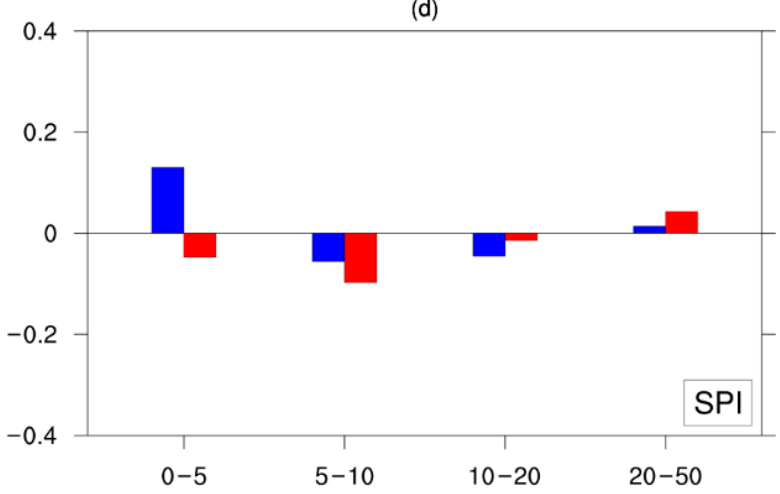

(f)

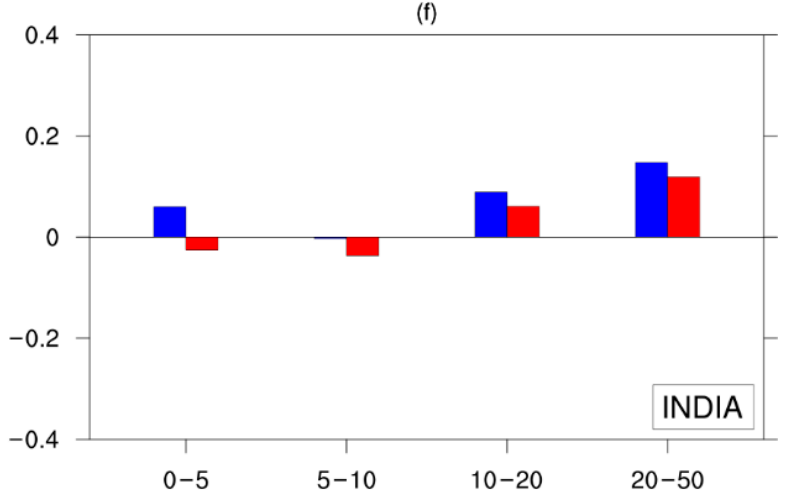

Rainfall category $\left(\mathrm{mmday}^{-1}\right)$

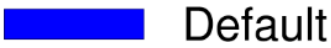

\section{ESASM}

Figure 13. Equitable threat score for different rainfall categories $\left(0-5,5-10,10-20\right.$ and 20-50 mmday $\left.{ }^{-1}\right)$ for the year 2002 over (f) the whole of India and (a-e) five homogeneous regions. 
(a)

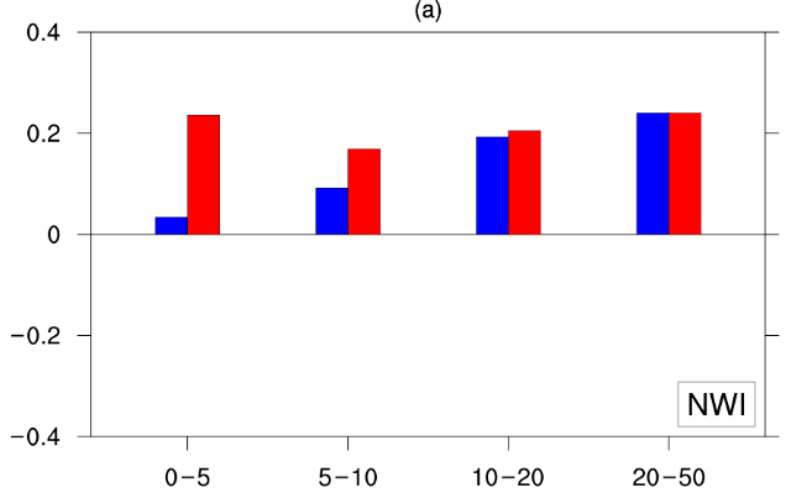

(c)

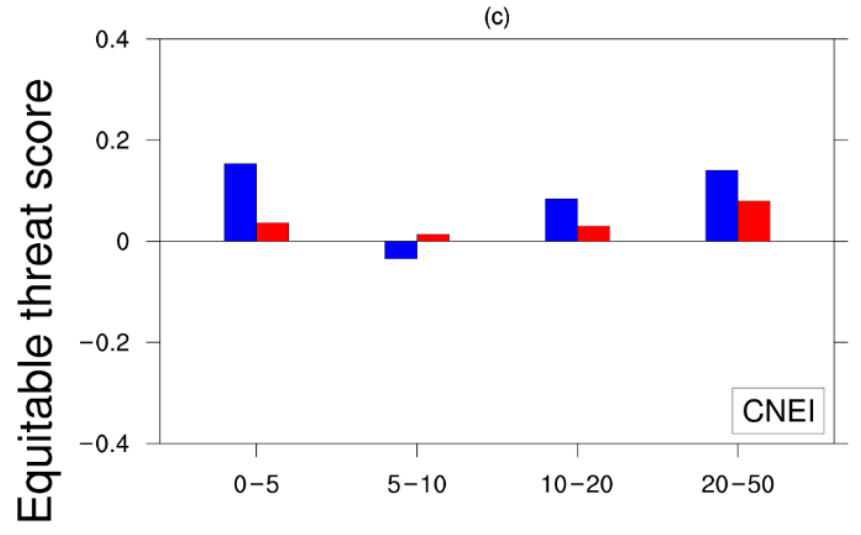

(e)

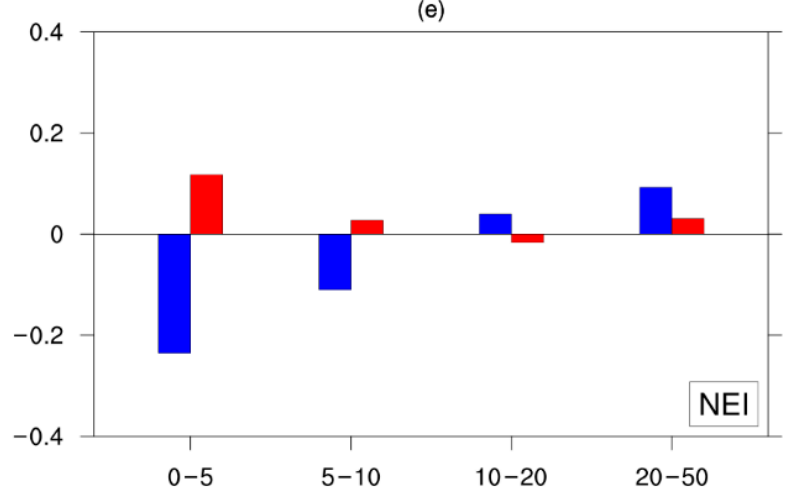

(b)

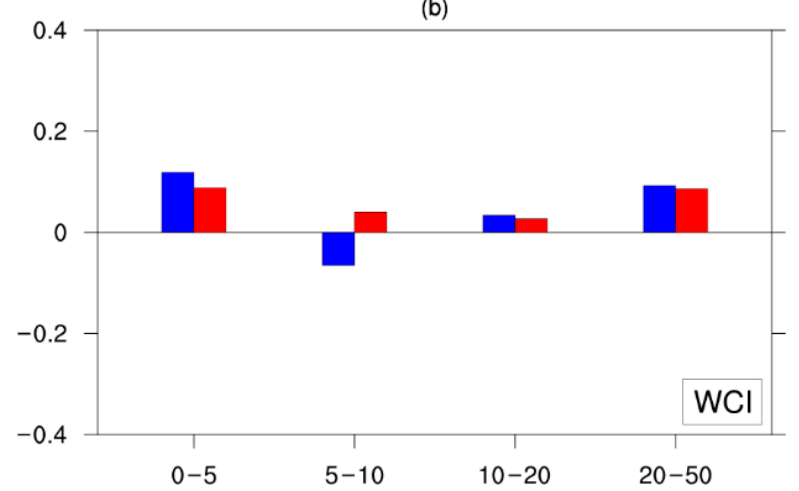

(d)

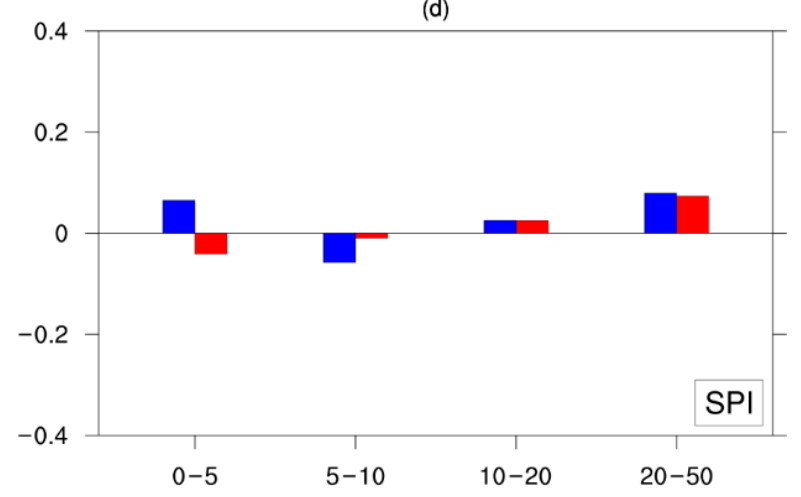

(f)

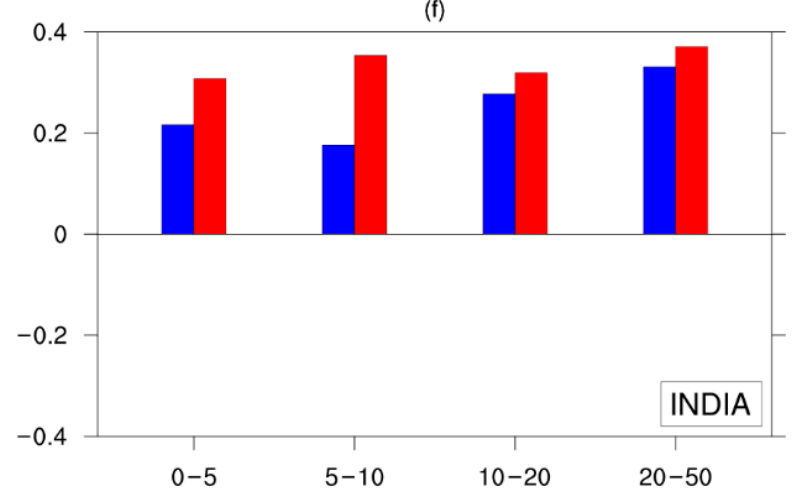

Rainfall category (mmday ${ }^{-1}$ )

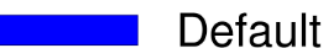

ESASM

Figure 14. Same as Figure 13, but for the year 2011.

\section{Discussion}

In this study, the impact of the soil moisture initialization technique in the model RegCM4 was investigated by incorporating high-resolution satellite-derived soil moisture data from ESA-CCI. In order to evaluate this aspect, seasonal simulations were conducted during two specific years, viz., 2002 (deficit monsoon year) and 2011 (normal monsoon year) with the default as well as modified soil moisture. A comprehensive evaluation was carried out based on the three essential parameters, viz., surface temperature, soil moisture and rainfall. These parameters were investigated regarding their distribution and accuracy at different temporal and spatial scales. 
The surface temperature distribution clearly noticed that model ability was relatively better when initialized with soil moisture data from the ESA. The magnitude and distribution of the temperature were better predicted by the model although having warm and cold biases over various regions of the country. In comparison to the default configuration, RegCM4 reduced the surface temperature biases significantly in the ESA setup. Statistical values, such as correlation and standard deviation, are consistently better using ESA soil moisture data. Simulated soil moisture was higher in RegCM4 than ESA-CCI, but when initialized using ESA soil moisture, it lowered the magnitude of soil moisture and portrayed better performance. Rainfall validation demonstrated that the model showed superior ability when initialized with ESA soil moisture on a seasonal and monthly scale. However, the model could not accurately predict the temporal variation of daily rainfall. Studies on soil moisture initialization with RegCM over other regions across the globe also highlighted similar abilities. Over the European region, Patarcic and Brancovic [30] investigated the ability of RegCM3 and found reduction (enhancement) in systematic errors (deterministic ability) of RegCM3 when initialized with high-resolution soil moisture. Over Asia, Liu et al. [31] mentioned that RegCM4 with higher initial soil moisture reduced the surface temperature and consequently increased the rainfall, although the impact was greater in mid-latitude areas compared to the tropics. This study also highlighted that temperature (rainfall) response was stronger (weaker) over India. Hu et al. [38] indicated that description of soil moisture with RegCM2 affected the model bias over China. Similar studies with other models (e.g., Weather Research and Forecasting Model) also showed that the ability scores and frequency bias of rainfall and root mean square of temperature were improved when using soil moisture data from global forecast systems [72].

Although, RegCM4 with the ESA setup appeared to ameliorate the performance, improvement is still necessary. Careful examination proclaimed that the model performance deteriorated, particularly during the extreme monsoon year (2002), although it showed acceptable accuracy during the normal monsoon year (2011). Major association of the poor ability during 2002 was the inefficiency to pick up various epochs of ISM precisely and thereby showed early onset and delayed withdrawal. However, it was also recognized that simulated rainfall was surprisingly low during the peak monsoon months, viz., July and August during 2011 (normal). In addition, rainfall was extremely high in June and July during 2002 (deficit). This indicated that RegCM4 would not be able to capture the contrasting features of ISM accurately. In brief, soil moisture initialization can significantly improve the model's ability in simulating weather/climate features and hence should be paid more attention. Our overall analysis infers significant improvement in the model's ability in simulating surface temperature and rainfall distribution when using high-resolution ESA soil moisture data, albeit that temporal variation in lacunae noticed. ETS of rainfall was higher with the ESA setup.

\section{Conclusions}

This study provided a primary assessment of realistic soil moisture initialization through seasonal simulation of ISM using the regional model. In summary, we found RegCM4 was sensitive to soil moisture initialization and consequently imparts potential improvement in simulating surface temperature and rainfall when initialized with highresolution, satellite-derived soil moisture data. Although, the model showed reasonable ability in a normal year, it still had difficulty in simulating different epochs of monsoon, particularly in extreme years. Further investigation is therefore required to enhance the model's ability.

\section{Limitation and Future Studies}

The investigations presented here are preliminary ideas for similar modeling studies in the future. Thus, systematic investigation with the added number of extreme years may reproduce more robust results. In addition, it is also important to test the model's ability using soil moisture data from different sources. 
Author Contributions: Conceptualization, S.M.; methodology, S.M.; software, S.M. and S.N.; validation, S.M., S.N. and K.S.S.; formal analysis, S.M. and S.N.; investigation, S.M., S.N. and H.P.N.; data curation, S.M.; writing — original draft preparation, S.M.; writing—review and editing, S.M., S.N., K.S.S., H.P.N. and S.D.; visualization, S.M., S.N. and S.D.; supervision, S.M. All authors have read and agreed to the published version of the manuscript.

Funding: This research received no external funding.

Institutional Review Board Statement: Not applicable.

Informed Consent Statement: Not applicable.

Data Availability Statement: The ERA-Interim reanalysis, sea-surface temperature, soil characteristics, soil moisture and other geophysical data used in this study are obtained from the http: / / clima-dods.ictp.it/regcm4/ accessed on 20 September 2020). Rainfall and temperature analysis data used for validation are freely available from the India Meteorological Department.

Acknowledgments: The authors would like to acknowledge the Indian Institute of Technology (IIT), Kharagpur, India, for providing necessary facilities to conduct this research work. Authors sincerely acknowledge A.N.V. Satyanarayana, IIT, Kharagpur, India, for the suggestions and advice towards the improvement of this research work. International Center for Theoretical Physics (ICTP, Italy) is gratefully acknowledged for providing the RegCM4 model source code (https:/ / github. com/ictp-esp/RegCM; accessed on 10 July 2020) and input datasets (http:/ / clima-dods.ictp.it/ regcm4/; accessed on 20 September 2020). IMD is duly recognized for providing the high-resolution temperature and rainfall analysis datasets. Various reanalysis and observation data from different sources such as ERA-Interim, NOAA and others are also properly recognized.

Conflicts of Interest: The authors declare no conflict of interest.

\section{References}

1. Steiner, A.L.; Pal, J.S.; Rauscher, S.A.; Bell, J.L.; Diffenbaugh, N.S.; Boone, A.; Sloan, L.C.; Giorgi, F. Land surface coupling in regional climate simulations of the West African monsoon. Clim. Dyn. 2009, 33, 869-892. [CrossRef]

2. Moufouma-Okia, W.; Rowell, D.P. Impact of soil moisture initialisation and lateral boundary conditions on regional climate model simulations of the West African Monsoon. Clim. Dyn. 2010, 35, 213-229. [CrossRef]

3. Douville, H. Relative contribution of soil moisture and snow mass to seasonal climate predictability: A pilot study. Clim. Dyn. 2010, 34, 797-818. [CrossRef]

4. Bisselink, B.; Van Meijgaard, E.; Dolman, A.J.; De Jeu, R.A.M. Initializing a regional climate model with satellite-derived soil moisture. J. Geophys. Res. Atmos. 2011, 116. [CrossRef]

5. Saha, S.K.; Halder, S.; Kumar, K.K.; Goswami, B.N. Pre-onset land surface processes and 'internal' interannual variabilities of the Indian summer monsoon. Clim. Dyn. 2011, 36, 2077-2089. [CrossRef]

6. Van den Hurk, B.; Doblas-Reyes, F.; Balsamo, G.; Koster, R.D.; Seneviratne, S.I.; Camargo, H. Soil moisture effects on seasonal temperature and precipitation forecast scores in Europe. Clim. Dyn. 2012, 38, 349-362. [CrossRef]

7. Suarez, A.; Mahmood, R.; Quintanar, A.I.; Beltran-Przekurat, A.; Pielke Sr, R. A comparison of the MM5 and the Regional Atmospheric Modeling System simulations for land-atmosphere interactions under varying soil moisture. Tellus A Dyn. Meteorol. Oceanogr. 2014, 66, 21486. [CrossRef]

8. Chakravorty, A.; Chahar, B.R.; Sharma, O.P.; Dhanya, C.T. A regional scale performance evaluation of SMOS and ESA-CCI soil moisture products over India with simulated soil moisture from MERRA-Land. Remote Sens. Environ. 2016, 186, 514-527. [CrossRef]

9. Lai, X.; Wen, J.; Cen, S.; Huang, X.; Tian, H.; Shi, X. Spatial and temporal soil moisture variations over China from simulations and observations. Adv. Meteorol. 2016, 2016, 4587687. [CrossRef]

10. Sathyanadh, A.; Karipot, A.; Ranalkar, M.; Prabhakaran, T. Evaluation of soil moisture data products over Indian region and analysis of spatio-temporal characteristics with respect to monsoon rainfall. J. Hydrol. 2016, 542, 47-62. [CrossRef]

11. Shrivastava, S.; Kar, S.C.; Sharma, A.R. Soil moisture variations in remotely sensed and reanalysis datasets during weak monsoon conditions over central India and central Myanmar. Theor. Appl. Climatol. 2017, 129, 305-320. [CrossRef]

12. Nayak, S.; Maity, S.; Singh, K.S.; Nayak, H.P.; Dutta, S. Influence of the Changes in Land-Use and Land Cover on Temperature over Northern and North-Eastern India. Land 2021, 10, 52. [CrossRef]

13. Nayak, S.; Mandal, M. Examining the impact of regional land use and land cover changes on temperature: The case of Eastern India. Spat. Inf. Res. 2019, 27, 601-611. [CrossRef]

14. Nayak, S.; Mandal, M. Impact of land use and land cover changes on temperature trends over India. Land Use Policy 2019, 89, 1166-1173. [CrossRef]

15. Giorgi, F.; Coppola, E.; Solmon, F.; Mariotti, L.; Sylla, M.B.; Bi, X.; Elguindi, N.; Diro, G.T.; Nair, V.; Giuliani, G.; et al. RegCM4: Model description and preliminary tests over multiple CORDEX domains. Clim. Res. 2012, 52, 7-29. [CrossRef] 
16. Dutta, S.K.; Das, S.; Kar, S.C.; Mohanty, U.C.; Joshi, P.C. Impact of downscaling on the simulation of seasonal monsoon rainfall over the Indian region using a global and mesoscale model. Open Atmos. Sci. J. 2009, 3, 104-123. [CrossRef]

17. Maurya, R.K.S.; Sinha, P.; Mohanty, M.R.; Mohanty, U.C. Coupling of community land model with RegCM4 for Indian summer monsoon simulation. Pure Appl. Geophys. 2017, 174, 4251-4270. [CrossRef]

18. Maity, S.; Mandal, M.; Nayak, S.; Bhatla, R. Performance of cumulus parameterization schemes in the simulation of Indian Summer Monsoon using RegCM4. Atmósfera 2017, 30, 287-309. [CrossRef]

19. Maity, S.; Satyanarayana, A.N.V.; Mandal, M.; Nayak, S. Performance evaluation of land surface models and cumulus convection schemes in the simulation of Indian summer monsoon using a regional climate model. Atmos. Res. 2017, 197, 21-41. [CrossRef]

20. Nayak, S.; Mandal, M.; Maity, S. Customization of regional climate model (RegCM4) over Indian region. Theor. Appl. Climatol. 2017, 127, 153-168. [CrossRef]

21. Nayak, S.; Mandal, M.; Maity, S. RegCM4 simulation with AVHRR land use data towards temperature and precipitation climatology over Indian region. Atmos. Res. 2018, 214, 163-173. [CrossRef]

22. Nayak, S.; Mandal, M.; Maity, S. Performance evaluation of RegCM4 in simulating temperature and precipitation climatology over India. Theor. Appl. Climatol. 2019, 137, 1059-1075. [CrossRef]

23. Leng, G.; Huang, M.; Tang, Q.; Sacks, W.J.; Lei, H.; Leung, L.R. Modeling the effects of irrigation on land surface fluxes and states over the conterminous United States: Sensitivity to input data and model parameters. J. Geophys. Res. Atmos. 2013, 118, 9789-9803. [CrossRef]

24. Fennessy, M.J.; Shukla, J. Impact of initial soil wetness on seasonal atmospheric prediction. J. Clim. 1999, 12, 3167-3180. [CrossRef]

25. Douville, H.; Chauvin, F. Relevance of soil moisture for seasonal climate predictions: A preliminary study. Clim. Dyn. 2000, 16, 719-736. [CrossRef]

26. Pan, Z.; Arritt, R.W.; Gutowski, W.J., Jr.; Takle, E.S. Soil moisture in a regional climate model: Simulation and projection. Geophys. Res. Lett. 2001, 28, 2947-2950. [CrossRef]

27. Kanamitsu, M.; Lu, C.H.; Schemm, J.; Ebisuzaki, W. The predictability of soil moisture and near-surface temperature in hindcasts of the NCEP seasonal forecast model. J. Clim. 2003, 16, 510-521. [CrossRef]

28. Douville, H. Relevance of soil moisture for seasonal atmospheric predictions: Is it an initial value problem? Clim. Dyn. 2004, 22, 429-446. [CrossRef]

29. Tawfik, A.B.; Steiner, A.L. The role of soil ice in land-atmosphere coupling over the United States: A soil moisture-precipitation winter feedback mechanism. J. Geophys. Res. Atmos. 2011, 116. [CrossRef]

30. Patarcic, M.; Brankovic, C. Skill of 2-m temperature seasonal forecasts over Europe in ECMWF and RegCM models. Mon. Weather Rev. 2012, 140, 1326-1346. [CrossRef]

31. Liu, D.; Wang, G.; Mei, R.; Yu, Z.; Yu, M. Impact of initial soil moisture anomalies on climate mean and extremes over Asia. J. Geophys. Res. Atmos. 2014, 119, 529-545. [CrossRef]

32. Nayak, H.P.; Osuri, K.K.; Sinha, P.; Nadimpalli, R.; Mohanty, U.C.; Chen, F.; Rajeevan, M.; Niyogi, D. High-resolution gridded soil moisture and soil temperature datasets for the Indian monsoon region. Sci. Data 2018, 5, 1-17. [CrossRef] [PubMed]

33. Nayak, H.P.; Sinha, P.; Mohanty, U.C. Incorporation of surface observations in the LDAS and application to mesoscale simulation of pre-monsoon thunderstorms. Pure Appl. Geophys. 2021, 178, 565-582. [CrossRef]

34. Gianotti, R.L.; Zhang, D.; Eltahir, E.A. Assessment of the regional climate model version 3 over the maritime continent using different cumulus parameterization and land surface schemes. J. Clim. 2012, 25, 638-656. [CrossRef]

35. Llopart, M.; da Rocha, R.P.; Reboita, M.; Cuadra, S. Sensitivity of simulated South America climate to the land surface schemes in RegCM4. Clim. Dyn. 2017, 49, 3975-3987. [CrossRef]

36. Nayak, S.; Mandal, M.; Maity, S. Assessing the impact of Land-use and Land-cover changes on the climate over India using a Regional Climate Model (RegCM4). Clim. Res. 2021, in press. [CrossRef]

37. Bhatla, R.; Ghosh, S.; Mandal, B.; Mall, R.K.; Sharma, K. Simulation of Indian summer monsoon onset with different parameterization convection schemes of RegCM-4.3. Atmos. Res. 2016, 176, 10-18. [CrossRef]

38. Hu, Y.; Ding, Y.; Liao, F. An improvement on summer regional climate simulation over East China: Importance of data assimilation of soil moisture. Chin. Sci. Bull. 2010, 55, 865-871. [CrossRef]

39. Parinussa, R.M.; Yilmaz, M.T.; Anderson, M.C.; Hain, C.R.; De Jeu, R.A.M. An intercomparison of remotely sensed soil moisture products at various spatial scales over the Iberian Peninsula. Hydrol. Process. 2014, 28, 4865-4876. [CrossRef]

40. Pieczka, I.; Pongrácz, R.; André, K.S.; Kelemen, F.D.; Bartholy, J. Sensitivity analysis of different parameterization schemes using RegCM4.3 for the Carpathian region. Theor. Appl. Climatol. 2017, 130, 1175-1188. [CrossRef]

41. Pal, J.S.; Giorgi, F.; Bi, X.; Elguindi, N.; Solmon, F.; Gao, X.; Rauscher, S.A.; Francisco, R.; Zakey, A.; Winter, J.; et al. Regional climate modeling for the developing world: The ICTP RegCM3 and RegCNET. Bull. Am. Meteorol. Soc. 2007, 88, 1395-1410. [CrossRef]

42. Anthes, R.A. A cumulus parameterization scheme utilizing a one-dimensional cloud model. Mon. Weather Rev. 1977, 105, 270-286. [CrossRef]

43. Grell, G.A. Prognostic evaluation of assumptions used by cumulus parameterizations. Mon. Weather Rev. 1993, 121, 764-787. [CrossRef]

44. Emanuel, K.A. A scheme for representing cumulus convection in large-scale models. J. Atmos. Sc. 1991, 48, 2313-2329. [CrossRef] 
45. Tiedtke, M.I.C.H.A.E.L. A comprehensive mass flux scheme for cumulus parameterization in large-scale models. Mon. Weather Rev. 1989, 117, 1779-1800. [CrossRef]

46. Kain, J.S.; Fritsch, J.M. Convective parameterization for mesoscale models: The Kain-Fritsch scheme. In The representation of cumulus convection in numerical models. Meteorological Monographs. Am. Meteor. Soc. 1993, 165-170. [CrossRef]

47. Dickinson, R.E.; Errico, R.M.; Giorgi, F.; Bates, G.T.; Henderson-Sellers, A.; Kennedy, P.J. Biosphere-Atmosphere Transfer Scheme (BATS) Version 1e as Coupled to the NCAR Community Climate Model; NCAR Tech. Note NCAR/TN-3871STR; National Center for Atmospheric Research: Boulder, CO, USA, 1993.

48. Oleson, K.W.; Niu, G.Y.; Yang, Z.L.; Lawrence, D.M.; Thornton, P.E.; Lawrence, P.J.; Stöckli, R.; Dickinson, R.E.; Bonan, G.B.; Levis, S.; et al. Improvements to the Community Land Model and their impact on the hydrological cycle. J. Geophys. Res. Biogeosci. 2008, 113. [CrossRef]

49. Bonan, G.; Drewniak, B.; Huang, M. Technical Description of Version 4.5 of the Community Land Model (CLM); NCAR Technical Note NCAR/TN-503+ STR; National Center for Atmospheric Research: Boulder, CO, USA, 2013.

50. Kiehl, T.; Hack, J.; Bonan, B.; Boville, A.; Briegleb, P.; Williamson, L.; Rasch, J. Description of the NCAR Community Climate Model (CCM3); Technical Note (No. PB-97-131528/XAB.; NCAR/TN-420-STR); National Center for Atmospheric Research: Boulder, CO, USA, 1996.

51. Holtslag, A.A.M.; De Bruijn, E.I.F.; Pan, H.L. A high resolution air mass transformation model for short-range weather forecasting. Mon. Weather Rev. 1990, 118, 1561-1575. [CrossRef]

52. Bretherton, C.S.; McCaa, J.R.; Grenier, H. A new parameterization for shallow cumulus convection and its application to marine subtropical cloud-topped boundary layers. Part I: Description and 1D results. Mon. Weather Rev. 2004, 132, 864-882. [CrossRef]

53. Halder, S.; Dirmeyer, P.A.; Saha, S.K. Sensitivity of the mean and variability of Indian summer monsoon to land surface schemes in RegCM4: Understanding coupled land-atmosphere feedbacks. J. Geophys. Res. Atmos. 2015, 120, 9437-9458. [CrossRef]

54. Giorgi, F.; Bates, G.T. The climatological skill of a regional model over complex terrain. Mon. Weather Rev. 1989, 117, $2325-2347$. [CrossRef]

55. Steiner, A.L.; Pal, J.S.; Giorgi, F.; Dickinson, R.E.; Chameides, W.L. The coupling of the Common Land Model (CLM0) to a regional climate model (RegCM). Theor. Appl. Climatol. 2005, 82, 225-243. [CrossRef]

56. Chaudhari, H.S.; Shinde, M.A.; Oh, J.H. Understanding of anomalous Indian summer monsoon rainfall of 2002 and 1994. Quat. Int. 2010, 213, 20-32. [CrossRef]

57. Maity, S. Comparative assessment of two RegCM versions in simulating Indian Summer Monsoon. J. Earth Syst. Sci. 2020, 129, 1-23. [CrossRef]

58. Arakawa, A.; Schubert, W.H. Interaction of a cumulus cloud ensemble with the large-scale environment, Part I. J. Atmos. Sci. 1974, 31, 674-701. [CrossRef]

59. Pal, J.S.; Small, E.E.; Eltahir, E.A. Simulation of regional-scale water and energy budgets: Representation of subgrid cloud and precipitation processes within RegCM. J. Geophys. Res. Atmos. 2000, 105, 29579-29594. [CrossRef]

60. Zeng, X.; Zhao, M.; Dickinson, R.E. Intercomparison of bulk aerodynamic algorithms for the computation of sea surface fluxes using TOGA COARE and TAO data. J. Clim. 1998, 11, 2628-2644. [CrossRef]

61. Dorigo, W.; Wagner, W.; Albergel, C.; Albrecht, F.; Balsamo, G.; Brocca, L.; Chung, D.; Ertl, M.; Forkel, M.; Gruber, A.; et al. ESA CCI Soil Moisture for improved Earth system understanding: State-of-the art and future directions. Remote Sens. Environ. 2017, 203, 185-215. [CrossRef]

62. Dorigo, W.A.; Gruber, A.; De Jeu, R.A.M.; Wagner, W.; Stacke, T.; Loew, A.; Albergel, C.; Brocca, L.; Chung, D.; Parinussa, R.M.; et al. Evaluation of the ESA CCI soil moisture product using ground-based observations. Remote Sens. Environ. 2015, 162, 380-395. [CrossRef]

63. Dee, D.P.; Uppala, S.M.; Simmons, A.J.; Berrisford, P.; Poli, P.; Kobayashi, S.; Andrae, U.; Balmaseda, M.A.; Balsamo, G.; Bauer, D.P.; et al. The ERA-Interim reanalysis: Configuration and performance of the data assimilation system. Q. J. R. Meteorol. Soc. 2011, 137, 553-597. [CrossRef]

64. Loveland, T.R.; Reed, B.C.; Brown, J.F.; Ohlen, D.O.; Zhu, Z.; Yang, L.W.M.J.; Merchant, J.W. Development of a global land cover characteristics database and IGBP DISC over from $1 \mathrm{~km}$ AVHRR data. Int. J. Remote Sens. 2000, 21, 1303-1330. [CrossRef]

65. Reynolds, R.W.; Rayner, N.A.; Smith, T.M.; Stokes, D.C.; Wang, W. An improved in situ and satellite SST analysis for climate. J. Clim. 2002, 15, 1609-1625. [CrossRef]

66. Srivastava, A.K.; Rajeevan, M.; Kshirsagar, S.R. Development of a high resolution daily gridded temperature data set (1969-2005) for the Indian region. Atmos. Sci. Lett. 2009, 10, 249-254. [CrossRef]

67. Pai, D.S.; Sridhar, L.; Rajeevan, M.; Sreejith, O.P.; Satbhai, N.S.; Mukhopadhyay, B. Development of a new high spatial resolution $(0.25 \times 0.25)$ long period (1901-2010) daily gridded rainfall data set over India and its comparison with existing data sets over the region. Mausam 2014, 65, 1-18.

68. Liu, Y.Y.; Parinussa, R.M.; Dorigo, W.A.; De Jeu, R.A.; Wagner, W.; Van Dijk, A.I.J.M.; McCabe, M.F.; Evans, J.P. Developing an improved soil moisture dataset by blending passive and active microwave satellite-based retrievals. Hydrol. Earth Syst. Sci. 2011, 15, 425-436. [CrossRef]

69. Parthasarathy, B.; Munot, A.A.; Kothawale, D.R. All-India monthly and seasonal rainfall series: 1871-1993. Theor. Appl. Climatol. 1994, 49, 217-224. [CrossRef] 
70. Mesinger, F. Improvements in quantitative precipitation forecasts with the Eta regional model at the National Centers for Environmental Prediction: The 48-km upgrade. Bull. Am. Meteorol. Soc. 1996, 77, 2637-2650. [CrossRef]

71. Gilbert, G.K. Finley's tornado predictions. Am. Meteorol. J. 1884, 1, 166.

72. Zhang, H.; Liu, J.; Li, H.; Meng, X.; Ablikim, A. The Impacts of Soil Moisture Initialization on the Forecasts of Weather Research and Forecasting Model: A Case Study in Xinjiang, China. Water 2020, 12, 1892. [CrossRef] 